\title{
LA BIBLIOTECA DEL COLEGIO DE JESUITAS DE ALBACETE EN EL TRANCE DE LA EXPULSIÓN (1767)
}

\author{
POR \\ M. Dolores García Gómez \\ Universidad de Alicante
}

\section{RESUMEN}

Regesto de la composición de la biblioteca del Colegio de Jesuitas de Albacete, donde aparecen diferentes colecciones de libros allí conservados en los siglos XVII y XVIII. Por medio de este inventario se reflexiona sobre la evolución intelectual de la orden en estas centurias.

\section{ABSTRACT}

Library Index of Albacete Jesuit College, where are present different books collections preserved in the XVIIth and XVIIIth centuries. By this inventory the autor tries to understand the intellectual evolution of the Jesuit Order in these centuries.

Abundantes estudios demuestran hoy el interés pedagógico de la Compañia de Jesús, y sus frutos, igualmente estudiados, coinciden en la mayoría al demostrar tanto la eficacia de su gestión, como la crisis educativa que supuso la expulsión: la valoración acerca de los contenidos docentes de la doctrina ignaciana, opta en su mayoría por una aportación pedagógica positiva', por la adaptación a su entorno, e incluso por su acercamiento en el ideario pedagógico a las iniciati-

' A. MESTRE SANCHis, «Marco histórico. Iglesia, sociedad y educación», en Historia de la educación de la Iglesia en España, Vol. I, Madrid, 1995, p. 469.

Actas del I Congreso de Historia de la Iglesia y el Mundo Hispánico

Hispania Sacra, 52 (2000) 
vas docentes europeas ${ }^{2}$, sin que sus mismos autores dejen de recordarnos que frente a la prioridad del ideal ignaciano de la subordinación del saber a la moral, el lastre inmovilista de la Ratio Studiorum, fue convirtiendo la entusiasta labor inicial en una realidad conservadora y rígida. La Compania responde a la exigencia social de la educación, exigencia gestada bajo la influencia del humanismo y potenciada por las ambiciones de una burguesía y oligarquía local, a las que se afiadían las necesidades de las propias monarquías de "oficiales reales»" para administrar el reino ${ }^{3}$. El método pedagógico cuyo éxito había hecho posible que en sólo sesenta años se abrieran doscientos treinta y seis colegios, se apoyaba en un sistema bien estructurado, en el que se alentaba a la adquisición - de nuevos conocimientos, adaptándolos, en manuales y recopilaciones, para componer un ideal de intelectualidad descrito en su famoso programa de estudios, Ratio atque Institutio Studiorum Societatis lesu.

Pero mientras otras aportaciones no vayan constatando el progresivo enriquecimiento intelectual y cultural de la Orden, que tan brillantemente se inicio en estos aspectos, los pocos resultados con que contamos al respecto y los que ofrecen el estudio de la biblioteca del Colegio de Jesuitas de Albacete, nos muestran un progresivo estancamiento doctrinal ya alejado de las inquietudes iniciales ${ }^{4}$.

¿Había sido la Compañia una comunidad con interés real en el debate del saber? ¿Tenía, aúm en los Colegios de tan escasa relevancia como el que nos ocupa, las constantes que caracterizan un movimiento cultural?: en los Colegios, en efecto, había un cuerpo profesoral, se utilizaban cursos o temas manuscritos para la enseñanza, había ediciones impresas por la propia Orden para impartir las clases, mantenían una correspondencia culta con otros integrantes de la Orden y de otras Ordenes; todo ello, como señalan Giard o Aswhort, en teoría son las constantes básicas que le dan el carácter científico a comunidades como la Royal Society en el s.XVII, la Accademia del Cimento, o a los Enciclopedistas del s. XVIII

Las conclusiones que aportan el estudio que llevamos a cabo del Colegio de Albacete, tienen un significado menor dada su escasa relevancia en el entramado institucional de la Compañia, pero no dejan de tener un peso en la valoración general del papel educador de los jesuitas, dentro precisamente de estas premisa de ciudad de orden medio y de momento cultural en el panorama del s. XVIII, y a ese respecto, los resultados de que informan estos libros que formaban su acervo cultural, no son estimulantes.

\footnotetext{
${ }^{2}$ Cfr. Ibidem, M. Batllori, Bowen,

${ }^{3}$ L. VAUCELLES, «Les jesuites à l'âge baroque (1540-1640)", en Histoire des jesuites des Renaissance cua Lumières, CNRS, Bordeaux, 1996, pp. 14-16.

${ }^{4}$ L. GIARD, «Le devoir d'intelligence ou l'insertion des jesuites dans le monde du savoin», en Les jesuites à la Renaissance. Sisteme educatif et productions du savoir, PUF 1995, p. XXV.

$s$ Ibidem, XIV, XV, XXV.
}

Actas del I Congreso de Historia de la Iglesia y el Mundo Hispánico Hispania Sacra, 52 (2000) 
Nos llevan los libros, como otras veces, a conocer las atenciones intelectuales, el material didáctico, doctrinal, de que se valían esta decena de religiosos, para sus clases, para sus sermones, en esta ciudad manchega. Las bibliotecas de los aposentos de los padres jesuitas no dicen mucho a favor de su intención pedagógica ni de sus acercamientos a los movimientos docentes europeos: antes bien muestran que adolecen del inmovilismo doctrinal heredado de las rancias enseñanzas del s. XVII. ¿Era el común de las librerias de los jesuitas en este siglo? O sólo las pequeñas fundaciones, como el caso que nos ocupa, adolecían de este mal? $O$ quizás -todo es posible- no se correspondían los añejos libros de los estantes con la doctrina y docencia que impartían? iFormaban sus libros parte de una herencia $o$ aportación fundacional, de un adorno cultural con poco uso y significado? Todo es posible, aunque los libros imponen por lo general su trasparencia cultural con una fidelidad probada.

Nos sirve el informe de las temporalidades del Colegio de Jesuitas de Albacete, tras la expulsión de 1767 , para valorar las repercusiones culturales y sociales que se dieron como consecuencia de la expulsión de la Companfía de Jesús. Esta aportación que hoy iniciamos presenta la documentación sobre el inventario de sus bibliotecas y forma parte del trabajo que nos ocupa, en el que valoramos, entre otras atenciones, el carácter de estos fondos recogidos por un procedimiento riguroso, inusual y exhaustivo, según imponía la orden real ${ }^{6}$, de cómo debían ser inventariados los bienes jesufticos, que nos permiten acceder directamente a esos legados sin las manipulaciones comunes que en los traspasos y abandonos sufren estos fondos librarios, y nos sirven por ello como muestra significativa para un análisis intelectual. Se suman a este interés las características propias de pertenecer a una institución y de ser religiosa.

Nos planteamos, junto con las conclusiones que otros estudios han llevado a cabo, la vigencia de una cultura institucional que podía seguir en mayor o menor grado las directrices de la Ratio Studiorum. Hemos dudado de la aplicación del concepto cultural de institución como iniciativa de programa, a la vista de los resultados que ofrece la información de los inventarios de sus temporalidades en esta ciudad, que podemos considerar de rango menor en el conjunto de fundaciones de la Compañía de Jesús. El alcance y cohesión de algunos principios institucionales están bien presentes - hemos recordado la unidad de criterio pedagógico y otro tanto cabe señalar en lo relativo al programa administrativo, la unidad organizativa, al modelo jerárquico-, tal y como informa la prolija descripción de los

\footnotetext{
${ }^{6}$ Real Cédula comprehensiva de la Instrucción de lo que se deberá observar para inventariar los libros y papeles existentes en las casas que han sido de los regulares de la Compañia en todos los dominios de S.M. en Colección General de las Providencias hasta aqui tomadas por el Gobierno y sobre el extrañamiento y ocupación de temporalidades de los regulares de la Compañía que existen en los dominios de S.M. de España, Indias e Islas Filipinas a consecuencia del Real Decreto de 27 de febrero y Pragmática Sanción de 2 de abril de ese afio. 1767-1784, XVII, pp. 65-73.
} 
manuscritos detallados en los inventarios. Sin embargo, la relación de sus librerias, o bibliotecas, no cumple por algunas ausencias básicas la norma institucional, dejando abierta la pregunta de hasta que punto había una coherencia en el plan institucional de algunas fundaciones de la Compañía de Jesús, en la medida que las adquisiciones y pertenencias de algunas obras de la biblioteca puedan reflejar una unidad de criterio doctrinal derivada de objetivos institucionales prefijados según los principios pedagógicos para los que se llevó a efecto esta fundación. El comentario de esas presencias y ausencias del conjunto librario solo los futuros estudios podrán demostrar si se cumplía en cada una de sus fundaciones.

Bien diversas son las influencias que pueden afectar a la formación de una biblioteca. Unificar los criterios entre bibliotecas de distintos periodos de creación y evolución quizás es tarea imposible. Son sabidas las diversificaciones ideológicas de una biblioteca, cuyos orígenes son resultado de complejas iniciativas fundacionales, de sucesivas aportaciones, no solo materiales sino también las que imponen los cambios ideológicos de cada momento.

En los libros de esta biblioteca reconocemos las constantes doctrinales que instituía la norma o que son el común de una biblioteca religiosa de cierta importancia, como lo son por ejemplo las obras de teología moral -y en menor medida la de dogmática- de los padres de la propia Compañía de Jesús, y también los afectos a la Orden asi como la ausencia de los proscritos por la misma. Estas presencias si pueden constituir un eje temático, que por otra parte no tienen suficiente entidad para definirles una intención establecida.

\section{INVENTARIO DE LAS TEMPORALIDADES DEL COLEGIO DE JESUTTAS DE AlBaCETE}

El Legajo C-313, sección Municipios del Archivo Histórico de Albacete contiene siete expedientes acerca de los inventarios de las temporalidades de los jesuitas expulsos. La numeración que tienen estos expedientes, que hemos respetado, está dada por el Archivo para su identificación sin que tenga otro significado. Cuatro de los expedientes atienden a inventarios de obras impresas y manuscritos y el resto a bienes raices.

Los Inventarios de libros corresponden a cuatro recuentos distintos del mismo fondo librario, tres de ellos efectuados en las fechas de la expulsión -27 de abril de 1767, consta en uno de ellos-, y otro, cinco afios después como dotación del envío los libros al obispado de Cartagena. Cada uno de los recuentos llevados a cabo en el momento de la expulsión tiene dos ordenaciones: la separación real de los libros que pertenecían a distintos padres de la orden, y la elegida de criterio alfabético. Uno de estos inventarios tiene un criterio mayor de ordenación, estableciendo bloques temáticos y dentro de ellos el orden alfabético, aunque no recoge la totalidad de los libros referida en los otros inventarios. 


\section{INVENTARIO DE LA BIBLIOTECA}

\begin{tabular}{|c|c|c|c|c|c|c|}
\hline Ref. & Tam. & Vol. & Autor & Titulo & Lugar & Año \\
\hline 14 & $4^{\circ}$ & 1 & Amaral, Pedro & Canticum Marianum & Evora & 1709 \\
\hline 2 & Fol & 1 & Abulense, Juan Sancho & $\begin{array}{l}\text { Selecta et Practica } \\
\text { Disputationes rerum }\end{array}$ & Madrid & 1624 \\
\hline 3 & $4^{\circ}$ & 1 & Busenbaum, Herman & Medulla Theologica Moralis & Barcelona & \\
\hline 4 & $4^{\circ}$ & 1 & Busenbaum, P.Herman & Medulla Theologica Moralis & Madrid & 1666 \\
\hline 5 & $4^{\circ}$ & 1 & Busenbaum, P.Herman & Metulla Theologica Moralis & Madrid & 1692 \\
\hline 6 & $4^{\circ}$ & 2 & Calatayud, Pedro & Misiones y Sermones & Madrid & 1754 \\
\hline 7 & $4^{\mathrm{a}}$ & 2 & Claus, José Ignacio & Specillegium cateticum? & Venecia & 1646 \\
\hline 8 & $4^{0}$ & 1 & Cliquet,Joseph Faustino & $\begin{array}{l}\text { Epitome florido o Flor } \\
\text { compendio de teologia moral }\end{array}$ & Madrid & 1740 \\
\hline 9 & $4^{\circ}$ & 1 & Hurtado, Gaspar & Tractatus de matrimonio & Alcala & 1627 \\
\hline 10 & fol. & 1 & Duran, Juan & $\begin{array}{l}\text { Sermones panegiricos de Cristo } \\
\text { y Maria }\end{array}$ & Madrid & 1710 \\
\hline 11 & fol. & 2 & Duran, Juan & Sermones panegiricos & Madrid & 1714 \\
\hline 12 & fol. & 1 & Duran, Juan & Santoral serafico y querubico & Madrid & 1718 \\
\hline 13 & $4^{\circ}$ & 1 & $\begin{array}{l}\text { Echeverre, Francisco } \\
\text { Miguel }\end{array}$ & Platicas doctrinales & Madrid & 1728 \\
\hline 14 & $4^{a}$ & 14 & Espinosa, Antonio & Historia del pueblo de Dios & Madrid & 1752 \\
\hline 15 & $4^{\circ}$ & 4 & Espinosa, P.Antonio & Historia del pueblo cristiano & Madrid & 1755 \\
\hline 16 & $4^{\circ}$ & 1 & Fernandez, Antonio & Espejo de sacerdotes & Valencia & 1762 \\
\hline 17 & $8^{\circ}$ & 1 & Ignacio, Martin & Instructionem sacerdotum & Lyon & 1609 \\
\hline 18 & fol & 1 & & $\begin{array}{l}\text { Fundamento de la iglesia y } \\
\text { obispado de Cartagena }\end{array}$ & Madrid & 1756 \\
\hline 19 & $4^{a} \mathrm{~m} \cdot \mathrm{m}$. & 1 & Gener, Juan Bautista & Scolstica vindicata & Génova & 1766 \\
\hline 20 & fol & 2 & Gutierrez, Miguel & Praxis Teologia mistica & Roma & 1745 \\
\hline 21 & fol & 1 & Gutiemez, Ildefonso & Teologia moralis & Madrid & 1718 \\
\hline 22 & for & 2 & & Institutum Societatis Iesu & Praga & 1756 \\
\hline 23 & $4^{\circ}$ & 1 & Arzobispo Paris & Instruccion Pastoral & Cons... & 1763 \\
\hline 24 & $4^{\circ}$ & 1 & & La juventud triunfante & Valencia & 1750 \\
\hline 25 & $4^{\circ}$ & 1 & $\begin{array}{l}\text { Laselve, La Selva, } \\
\text { Zacarias }\end{array}$ & Annus apostolicus & Venecia & 1755 \\
\hline 26 & fol & 1 & $\begin{array}{l}\text { Lusitano, Manuel } \\
\text { Rodrigo }\end{array}$ & Questiones Regulares & Salamanca & 1601 \\
\hline
\end{tabular}

Actas del I Congreso de Historia de la Iglesia y el Mundo Hispánico Hispania Sacra, 52 (2000) 


\begin{tabular}{|c|c|c|c|c|c|c|}
\hline Ref. & Tam. & Vol. & Autor & Titulo & Lugar & Año \\
\hline 27 & fol. & 1 & Murillo, Velarde Pedro & $\begin{array}{l}\text { Historia de la providencia de } \\
\text { las Filipinas de la Compañía } \\
\text { de Jes }\end{array}$ & Manila & 1749 \\
\hline 28 & $8^{\circ}$ & 1 & Mercado, Pedro & $\begin{array}{l}\text { Practica de los monasterios } \\
\text { eclesiasticos }\end{array}$ & Sevilla & 1676 \\
\hline 29 & $8^{\circ}$ & 1 & $\begin{array}{l}\text { Nieremberg, Juan } \\
\text { Eusebio }\end{array}$ & $\begin{array}{l}\text { Aprecio y estima de la divina } \\
\text { gracia }\end{array}$ & Madrid & 1714 \\
\hline 30 & $4^{\circ}$ & 1 & $\begin{array}{l}\text { Navarro, Martin } \\
\text { Azpilicueta }\end{array}$ & $\begin{array}{l}\text { Mamual de confesores y } \\
\text { penitentes }\end{array}$ & Valladolid & 1560 \\
\hline 31 & $4^{\circ}$ & 1 & Navarro, Pedro & $\begin{array}{l}\text { De ablatorum restitutione in } \\
\text { foro conscientia }\end{array}$ & Toledo & 1596 \\
\hline 32 & $4^{\circ}$ & 1 & Najera, Manuel & Cuaresma segunda & Madrid & 1680 \\
\hline 33 & fol & 2 & Ormaza, José & Grano del Evangelio & Madrid & \\
\hline 34 & fol & & Ormaza, P. José & El sabio dichoso & Madrid & 1662 \\
\hline 35 & fol. & 2 & Oviedo, Franciseo & De fide spe et charitate & Lyon & 1651 \\
\hline 36 & fol. & 1 & Oviedo, P. Francisco & $\begin{array}{l}\text { Respondentes prima et } \\
\text { secundae Divi Thomae }\end{array}$ & Lyon & 1646 \\
\hline 37 & $8^{\circ}$ & 1 & Valdes, Andres & $\begin{array}{l}\text { Expostulatio appologetica } \\
\text { pro Societate Iesu }\end{array}$ & Lyon & 1606 \\
\hline 38 & $8^{\circ}$ & 2 & Vieira, Antonio & Sermones varios & Madrid & 1611 \\
\hline 39 & $8^{a}$ & & Viera, P. Antonio & Sermones varios & Madrid & 1631 \\
\hline 40 & fol & 1 & Illescas, Gonzalo & Historia pontifical y católica & Barcelona & 1589 \\
\hline 41 & fol & 1 & Iribarre, Juan & Tractatus de actibus humaanis & Zaragoza & 1646 \\
\hline 42 & $8^{\circ}$ & 1 & San Juan Crisostomo & $\begin{array}{l}\text { Comentarius in Acta } \\
\text { Apostolunum }\end{array}$ & Amberes & 1550 \\
\hline 43 & fol. & 2 & Panes, Antonio & $\begin{array}{l}\text { Cronica de la provincia de San } \\
\text { Juan Bautista de religiosos } \\
\text { menores descalzos de la } \\
\text { regular observanciade nuestro } \\
\text { Serafico P. San Francisco }\end{array}$ & Valencia & 1666 \\
\hline 44 & fol & 1 & Occa, Diego & $\begin{array}{l}\text { Doce pares de sagrados } \\
\text { panegiricos }\end{array}$ & Valencia & 1681 \\
\hline 45 & 4m.m. & 1 & Prieratte, Silvestre & $\begin{array}{l}\text { Silvestrina suma quae suma } \\
\text { sumarum merito nuncupatur }\end{array}$ & Lyon & 1694 \\
\hline 46 & $4^{0}$ & 1 & Quesna, Bartolome & Sermones & Lisboa & 1694 \\
\hline 47 & fol. & 1 & Sarmiento, Diego & Index expurgatorius hispanus & Madrid & 1707 \\
\hline
\end{tabular}

Actas del I Congreso de Historia de la Iglesia y el Murndo Hispánico

Hispania Sacra, 52 (2000) 


\begin{tabular}{|c|c|c|c|c|c|c|}
\hline Ref. & Tam. & Vol. & Autor & Tifulo & Lugar & Ario \\
\hline 48 & fol. & 1 & Ribadeneira, Pedro & $\begin{array}{l}\text { Vida del Paire Ignacio de } \\
\text { Loyola }\end{array}$ & Madrid & 1594 \\
\hline 49 & $4^{0}$ & 1 & Turlot, Nicolas & Thesaurus doctrina cristiana & Venecia & 1736 \\
\hline 50 & $4^{0}$ & 7 & Vieira, P.Antonio & Sermones varios & Madrid & 1662 \\
\hline 51 & fol. & 1 & Verde, Francisco & $\begin{array}{l}\text { Theologia fundamentalis } \\
\text { Caramuelis }\end{array}$ & Lyon & 1662 \\
\hline 52 & $4^{a}$ & 3 & & Sermones varios & & \\
\hline 53 & fol & 1 & Pueyo Abadia, Francisco & Espejo evangelico & Madrid & \\
\hline 54 & $8^{a} \mathrm{~m} \cdot \mathrm{m}$. & 1 & & Obras al maestro Juan de Avila & & \\
\hline 55 & fol. & 1 & Guadalajara, Marcos & Historia Pontifical & Barcelona & 1630 \\
\hline 56 & $8^{\circ}$ & 21 & Granada, Luis & Vida y Obras del mismo & Madrid & 1711 \\
\hline 57 & $4^{0}$ & 5 & Garau, Francisco & $\begin{array}{l}\text { Las tres maximas - Ideas del } \\
\text { mismo }\end{array}$ & & \\
\hline 58 & fol. & 2 & Alcaraz, Bartolome & $\begin{array}{l}\text { Chrono Historia de la } \\
\text { Compañia... de la provincia } \\
\text { de Toledo }\end{array}$ & Madrid & \\
\hline 59 & fol & 1 & Alcaraz P. Bartolome & $\begin{array}{l}\text { Vida virtudes y milagros de } \\
\text { San Julian obispo de Cnenca }\end{array}$ & Madrid & 1692 \\
\hline 60 & $4^{8}$ & 1 & Alcaraz, Jose & Consejos de la sabiduria & Madrid & 1691 \\
\hline 61 & 8 & 12 & Calino, Cesar & $\begin{array}{l}\text { Consideraciones o Discursos } \\
\text { familiares }\end{array}$ & Venecia & 1749 \\
\hline 62 & $8^{\circ}$ & 10 & Calino P. Cesar & $\begin{array}{l}\text { Diez lecciones sagradas y } \\
\text { morales }\end{array}$ & Venecia & 1758 \\
\hline 63 & $4^{\circ}$ & 1 & $\begin{array}{l}\text { Guimenio, (Guimenei), } \\
\text { Amadeo }\end{array}$ & $\begin{array}{l}\text { Adversus quonum dam } \\
\text { expostulationem contra non } \\
\text { nullos jesuitanum opiniones } \\
\text { morales }\end{array}$ & Madrid & 1644 \\
\hline 64 & $4^{\circ}$ & 1 & Garcia, Francisco & $\begin{array}{l}\text { Vida y virtudes de S. Ignacio } \\
\text { de Loyola }\end{array}$ & Madrid & 1685 \\
\hline 65 & fol & 1 & Lessio, Leandro & De iustitia et Iure & Sevilla & 1605 \\
\hline 66 & $4^{\circ}$ & 1 & Navarro, Gabriel & $\begin{array}{l}\text { Teologia mistica union y junta } \\
\text { perfecta }\end{array}$ & Madrid & 1651 \\
\hline 67 & fol & 1 & Moya, Mateo & $\begin{array}{l}\text { Selecta questiones exprecipuijs } \\
\text { theologia moralis }\end{array}$ & Madrid & 1660 \\
\hline 68 & fol & 2 & $\begin{array}{l}\text { Madre de Dios de la, } \\
\text { Alejandro }\end{array}$ & $\begin{array}{l}\text { Cronica de los padres descazos } \\
\text { de la Santisima Trinidad }\end{array}$ & Alcala & 1706 \\
\hline
\end{tabular}

Actas del I Congreso de Historia de la Iglesia y el Mundo Hispánico Hispania Sacra, 52 (2000) 


\begin{tabular}{|c|c|c|c|c|c|c|}
\hline Ref. & Tam. & Vol. & Autor & Titulo & Lugar & Aก๊o \\
\hline 69 & fol & 2 & Machado, Juan & Perfecto confesor y cura de alm & Madrid & 1647 \\
\hline 70 & fol & 8 & Vazquez, Gabriel & $\begin{array}{l}\text { Comentarios a las obras de } \\
\text { Santo Tomas }\end{array}$ & Alcala & 1610 \\
\hline 71 & fol & 1 & Valderrama, Pedro & $\begin{array}{l}\text { Ejercicios espirituales para } \\
\text { todos los dias de la Cuaresma }\end{array}$ & Zaragoza & 1606 \\
\hline 72 & fol & 1 & Villalobos, Enrique & $\begin{array}{l}\text { Suma de la teologia moral y } \\
\text { canonica }\end{array}$ & Barcelona & 1640 \\
\hline 73 & $4^{\circ}$ & 2 & Angel Pascual, Miguel & Sermones panegiricos & & 1705 \\
\hline 74 & $8^{\circ}$ & 1 & Aranda, Gabriel & E] artifice perfecto & Sevilla & 1696 \\
\hline 75 & $4^{\circ}$ & 2 & Bono, Francisco & Cuaresma entera & Valencia & 1741 \\
\hline 76 & $4^{\circ}$ & 1 & Benedicto XIV & Casus conscientia & Ferrara & 1760 \\
\hline 77 & $8^{\circ}$ & 1 & Burdalue, Luis' & Retiro espiritual & Madrid & \\
\hline 78 & $4^{\circ} \mathrm{m} \cdot \mathrm{m}$. & 1 & Biblia Sacra & Biblia Sacra & Amberes & 1664 \\
\hline 79 & $4^{0}$ & 16 & Davin, Diego & $\begin{array}{l}\text { Cartas edificantes escritas de } \\
\text { las misiones extrangeras }\end{array}$ & Madrid & $1757^{*}$ \\
\hline 80 & fol & 9 & Diana, Antoxio & $\begin{array}{l}\text { Resolutiones morales y la } \\
\text { suma de toda la obra }\end{array}$ & Madrid & $1645^{\prime \prime}$ \\
\hline 81 & fol & 1 & Fonseca, Cristobal & Vida de Christo Nuestro Señor & Toledo & 1598 \\
\hline 82 & fol & 1 & Ticinio Marsilio & Divini Platonis opera omnia & Lyon & 1547 \\
\hline 83 & $4^{0}$ & 1 & Fonperosa, Francisco & $\begin{array}{l}\text { Dias sagrados y geniales en la } \\
\text { canonizacion de San Francisco } \\
\text { de Borja }\end{array}$ & & \\
\hline 84 & fol & 1 & Martinez, Juan & $\begin{array}{l}\text { Theologia moralis questiones } \\
\text { praecipua }\end{array}$ & Alcala & 1654 \\
\hline 85 & $4^{0}$ & 1 & Madrid, Francisco Felix & Tentativa complutensis & Alcala & 1642 \\
\hline 86 & $4^{\circ}$ & 1 & Muniessa, Tomas & Cuaresma tercera & Barcelona & \\
\hline 87 & $4^{0}$ & 5 & Roxas, Martin & $\begin{array}{l}\text { Instruciones cristianas sobre } \\
\text { las dominicas del affo }\end{array}$ & Madrid & $1718^{*}$ \\
\hline 88 & $4^{0}$ & 1 & Ruidavalos, Julian & Los jovenes jesuitas & Madrid & 1728 \\
\hline 89 & fol & 1 & Sacchino, Francisco & $\begin{array}{l}\text { Historia Societatis Iesu pars } \\
\text { quarta }\end{array}$ & ¿ Jneulis? & 1661 \\
\hline 90 & $4^{\circ}$ & 13 & & Sermones varios & & \\
\hline 91 & fol & 1 & Tamburino, Tomas & Teologia moralis & Venecia & 1745 \\
\hline 92 & $4^{0} \mathrm{~m} \cdot \mathrm{m}$. & 1 & Torecilla, Martin & Compendio a la suma añadida & Madrid & 1698 \\
\hline 93 & fol & 2 & Torrecilla Fr. Martin & $\begin{array}{l}\text { Suma de todas las materias } \\
\text { morales }\end{array}$ & Madrid & 1691 \\
\hline
\end{tabular}

Actas del I Congreso de Historia de la Iglesia y el Mundo Hispánico Hispania Sacra, 52 (2000) 


\begin{tabular}{|c|c|c|c|c|c|c|}
\hline Ref. & Tom. & Vol. & Autor & Titulo & Lugar & Año \\
\hline 94 & fol. & 1 & Tonecilla Fr. Martin & $\begin{array}{l}\text { Examen de la potestad y } \\
\text { jurisdicion de los obispos }\end{array}$ & Madrid & 1682 \\
\hline 95 & fol & 1 & Torrecilla Fr. Martin & Comentarios morales & Madrid & 1684 \\
\hline 96 & fol & 1 & Biblia Sacra & Biblia Sacra & Francja & 1540 \\
\hline 97 & $8^{\circ}$ & 1 & Bonetta, Jose & Gracias de la Gracia & Zaragoza & 1706 \\
\hline 98 & fol & 3 & Bonacina, Martin & $\begin{array}{l}\text { Openum de morali theologia } \\
\text { et omnibus conscientis nodis }\end{array}$ & Lyon & 1639 \\
\hline 99 & fol & 1 & Bonacina P. Martin & Opera omnia & Lyon & 1639 \\
\hline 100 & fol & 1 & Babia, Luis & Historia pontifical y catolica & Madrid & 1607 \\
\hline 101 & $4^{\circ}$ & 1 & Calleja, Diego & $\begin{array}{l}\text { Talentos logrados en el buen } \\
\text { uso de los cinco sentidos }\end{array}$ & Madrid & 1700 \\
\hline 102 & fol & 1 & Cabrera, Juan & Crisis politica & Madrid & 1719 \\
\hline 103 & fol & 3 & $\begin{array}{l}\text { Causino(Causini), } \\
\text { Nicolas }\end{array}$ & La corte santa & Barcelona & 1696 \\
\hline 104 & $8^{\circ}$ & 1 & Casani, Jose & $\begin{array}{l}\text { Vida de San Estanislao de } \\
\text { Koska }\end{array}$ & Madrid & 1715 \\
\hline 105 & & 1 & Garcia, Francisco & Novena a San Frco. Javier & Madrid & 1757 \\
\hline 105 & $4^{\circ}$ & 3 & Gutierez, Andres & Sermones varios & Valencia & 1735 \\
\hline 106 & $4^{0}$ & 2 & $\begin{array}{l}\text { Gutierrez de la Sal } \\
\text { P. Antonio }\end{array}$ & Sermones varios & Madrid & 1738 \\
\hline 107 & $4^{0}$ & 1 & Angles, Antonio & Flores theologicarum & Burg0s & 1575 \\
\hline 108 & $4^{0}$ & 4 & Angel $_{i} P$. Miguel & El oyente perseverado & Valencia & 1690 \\
\hline 109 & $4^{0}$ & 1 & Angel i P. Miguel & El misionero instruido & Madrid & \\
\hline 110 & $4^{\circ}$ & 1 & Calascuella, Manuel & Vida del glorioso San Cayetano & Madrid & 1653 \\
\hline 111 & $4^{\circ}$ & 1 & $\begin{array}{l}\text { Valle de la Cerda, } \\
\text { Jeronimo }\end{array}$ & $\begin{array}{l}\text { Vida del dichoso Marcelo } \\
\text { Frco. Mattulte? }\end{array}$ & Madrid & 1640 \\
\hline 112 & $4^{\circ}$ & 1 & Caeano, Juan & Obras & Zaragoza & 1661 \\
\hline 113 & fol & 5 & Puente, Luis & Obras espirituales & Madrid & 1690 \\
\hline 114 & $4^{\circ}$ & 2 & Penix, Francisco & Sermones Cuadragesimales & Madrid & 1719 \\
\hline 115 & $4^{\circ}$ & 1 & Andrade, Alonso & Itinerario Historial & Madrid & 1660 \\
\hline 116 & $4^{\circ}$ & 21 & & $\begin{array}{l}\text { Apendice y Observaciones } \\
\text { sobre la conducta que ha tenido } \\
\text { el ministro de Portugal en los } \\
\text { negocios de los jesuitas }\end{array}$ & & \\
\hline 117 & $4^{\circ}$ & 1 & Cesareo, Sebastian & Sugilatis ingratitudines & & \\
\hline
\end{tabular}

Actas del I Congreso de Historia de la Iglesia y el Mundo Hispánico Hispania Sacra, 52 (2000) 


\begin{tabular}{|c|c|c|c|c|c|c|}
\hline Ref. & $T a m$ & Vol. & Autor & Titulo & Lugar & Año \\
\hline 118 & $4^{0}$ & 1 & Coninck, Egidio & De sacramentis et censuris & Lyon & 1619 \\
\hline 119 & $4^{0}$ & 2 & Castejon, Agustin & Voces del alma & Madrid & 1739 \\
\hline 120 & $4^{\circ}$ & 1 & Castejon P. Agustin & Glorias de la Virgen & Madrid & 1739 \\
\hline 121 & $8^{\circ}$ & 1 & Calisio, Cesar & $\begin{array}{l}\text { Leciones teologico morales } \\
\text { sobre el juego }\end{array}$ & Madrid & 1737 \\
\hline 122 & $4^{0}$ & 1 & Pozo, Andres & $\begin{array}{l}\text { Exortaciones a la devocion de } \\
\text { los santos angeles de la guarda }\end{array}$ & & \\
\hline 123 & $4^{\circ}$ & 1 & $\begin{array}{l}\text { Peinado, Ignacio } \\
\text { Francisco }\end{array}$ & De Generatione & Alcala & 1698 \\
\hline 124 & $4^{\circ}$ & 1 & 4 & $\begin{array}{l}\text { Sermones y papeles misticos, } \\
\text { impresos y manuescritos que } \\
\text { principian por Funesto Aparato } \\
\text { y concluyen con las Honras al } \\
\text { P. Man? }\end{array}$ & & \\
\hline \multirow{2}{*}{\multicolumn{7}{|c|}{$\begin{array}{l}\text { En esta forma se concluyo el inventario en el que mando su merced cesar, para continuarlo en el siguiente dia } \\
\qquad y \text { lo frmo en la villa de Albacete el mes de a mil setecientos sesenta y siete }\end{array}$}} \\
\hline & & & & & & \\
\hline 125 & $4^{\circ}$ & 2 & Guimenio P. Andres & $\begin{array}{l}\text { Adversu quorumdam } \\
\text { expostulatione contra non nulla } \\
\text { veritanum opinionem moralem }\end{array}$ & Valencia & 1661 \\
\hline 126 & fol & 1 & Abreu, Sebastian & $\begin{array}{l}\text { Institutio parrochi, seu } \\
\text { speculum parrochorum }\end{array}$ & Evora & 1665 \\
\hline 127 & $8^{\circ}$ & 1 & Casabuoni, Isacus & $\begin{array}{l}\text { Appendicula additionam sunt } \\
\text { Suetoni libelli seu illustribus } \\
\text { gramaticis et de claris thetoribus }\end{array}$ & & 1607 \\
\hline 128 & $8^{\circ}$ & 1 & & $\begin{array}{l}\text { Compendium phanum glorium } \\
\text { et gratianum Societas Iesu }\end{array}$ & Roma & 1580 \\
\hline 129 & fol & 1 & $\begin{array}{l}\text { Braulio de la Serma, } \\
\text { Marcos }\end{array}$ & $\begin{array}{l}\text { Espejo de la juventud moral } \\
\text { politico y cristiana }\end{array}$ & Madrid & 1664 \\
\hline 130 & fol & 1 & & Biblia Sacra & Lovaina & 1547 \\
\hline \multirow[t]{2}{*}{131} & $8^{\circ}$ & 4 & Becano, Martin & $\begin{array}{l}\text { De theologia escolastica - } \\
1^{A}-2^{\prime} \text { parte }\end{array}$ & Paris & 1625 \\
\hline & & & Becano P. Martin & $\begin{array}{l}\text { De theologia escolastica - } \\
3^{4} \text { parte }\end{array}$ & Paris & 1620 \\
\hline
\end{tabular}

Actas del I Congreso de Historia de la Iglesia y el Mundo Hispánico Hispania Sacra, 52 (2000) 


\begin{tabular}{|c|c|c|c|c|c|c|}
\hline Ref. & Tom. & Vol. & Autor & Titulo & Lugar & $A \tilde{o}$ \\
\hline & & & Becano P. Martin & $\begin{array}{l}\text { De theologia escolastica - } \\
2^{n} \text { parte }\end{array}$ & Lyon & 1620 \\
\hline 132 & $4^{\circ}$ & 1 & Busembaum P. Hermann & Medulla theologia moralis & Barcelona & 1703 \\
\hline 133 & $8^{\circ}$ & 1 & Fillucio P. Vicente & $\begin{array}{l}\text { Compendium questionem } \\
\text { moralium }\end{array}$ & Lyon & 1626 \\
\hline 134 & fol & 2 & Diana P. Antonio & $\begin{array}{l}\text { Resolutiones morales in tres } \\
\text { partes distributa }\end{array}$ & Lyon & 1630 \\
\hline 135 & fol & 2 & Diana P. Antonio & $\begin{array}{l}\text { Pars quinta in qua selectiores } \\
\text { casus conscientia breviter... }\end{array}$ & Madrid & 1640 \\
\hline 136 & fol & 2 & Diana P. Antonio & Pars sexta & Madrid & 1643 \\
\hline 137 & fol & 1 & Granada Fr. Luis & Introduccion al simbolo de la fe & Salamanca & 1583 \\
\hline 138 & fol & 1 & Junio P. Andres & $\begin{array}{l}\text { De providentia et } \\
\text { predestinatione }\end{array}$ & Lyon & 1678 \\
\hline \multirow[t]{4}{*}{139} & $4^{0}$ & 5 & Hurtado, Gaspar & De sacramentis - $1^{\circ}-2^{\circ}$ & Alcala & 1620 \\
\hline & & & Hurtado P. Gaspar & $\begin{array}{l}\text { De beatitudine actibus humanis } \\
\text { bontate et malitia habitibus } \\
\text { virtutibus et pecatis }\end{array}$ & Alcala & 1630 \\
\hline & & & Hurtado P. Gaspar & De iustitia et iure & Alcala & 1637 \\
\hline & & & Hurtado P. Gaspar & De Deo -primera parte & Madrid & 1641 \\
\hline 140 & fol & 2 & & $\begin{array}{l}\text { Institutum societeis Tesu seu. } \\
\text { ex.Congregationis Generalis } \\
\text { decimae quartae meliorem in } \\
\text { ordinem digestum autum ac } \\
\text { donus Rau.. }\end{array}$ & Praga & 1705 \\
\hline 141 & $8^{a}$ & 1 & Hurtado P. Gaspar & $\begin{array}{l}\text { Tractatus de matrimonio et } \\
\text { censuris }\end{array}$ & Lyon & 1620 \\
\hline 142 & $4^{\circ}$ & 2 & San Jose, Pedro & $\begin{array}{l}\text { Discursos morales para las } \\
\text { ferias menores de Quaresma }\end{array}$ & Alcala & 1552 \\
\hline \multirow[t]{2}{*}{143} & fol & 2 & Lacroix, Claudio & Adicciones al P.Busembaum & Lyon & 1629 \\
\hline & & & Lacroix Claudio & Theologia Moral & Lyon & 1729 \\
\hline \multirow[t]{2}{*}{144} & fol & 2 & Mendoza, Francisco & $\begin{array}{l}\text { Comentarii in quattuor libros } \\
\text { Regum }\end{array}$ & Coimbra & 1621 \\
\hline & & & Mendoza P. Francisco & $\begin{array}{l}\text { Comentarii in quattuor libros } \\
\text { Regum }\end{array}$ & Evora & 1624 \\
\hline 145 & $8^{\circ}$ & 5 & Marin, Juan & De actibus bumanis & Alcala & 1705 \\
\hline 146 & fol & 1 & Marin P. Juan & De pecatis & Alcala & 1706 \\
\hline
\end{tabular}

Actas del I Congreso de Historia de la Iglesia y el Mundo Hispánico Hispania Sacra, 52 (2000) 


\begin{tabular}{|c|c|c|c|c|c|c|}
\hline Ref. & Tam. & Vol. & Autor & Titulo & Lugar & $A \tilde{n} 0$ \\
\hline 147 & fol & 4 & Marin P. Juan & De libero arbitris & Alcala & 1706 \\
\hline 148 & fol & 5 & Marin P. Juan & De bonitate et malitia & Alcala & 1707 \\
\hline 149 & fol & 4 & Maria P. Juan & De vicione et beatitudine & Alcala & 1707 \\
\hline 150 & fol & 3 & Marin P. Juan & De merito & Alcala & 1707 \\
\hline 151 & fol & 3 & Marin P. Juan & De justificatione & Alcala & 1708 \\
\hline 152 & fol & 1 & Marix P. Juan & De fide & Alcala & 1708 \\
\hline 153 & fol & 1 & Marin P. Juan & De fide divina & Alcala & 1709 \\
\hline 154 & fol & 1 & Marin P. Juan & De scientia Dei & Alcala & 1710 \\
\hline 155 & fol & 1 & Marin P. Juan & De eucharistia & Madrid & 1712 \\
\hline 156 & fol & 1 & Marin P. Juan & De trinitate & Madrid & 1712 \\
\hline 157 & fol & 1 & Marin P. Juan & De sacramentis & Madrid & 1713 \\
\hline 158 & fol & 1 & Marin P. Juan & De baptismo & Madrid & 1713 \\
\hline 159 & fol & 1 & Marin P. Juan & De libero arbitrio & Madrid & 1714 \\
\hline 160 & fol & 1 & Marin P. Juan & De bonitate et malitia & Madrid & 1714 \\
\hline 161 & fol & 1 & Marin P. Juan & De voto & Madrid & 1714 \\
\hline 162 & fol & 1 & Marin P. Juan & De fide & Madrid & 1716 \\
\hline 163 & fol & 1 & Marin P. Juan & De spes et charitas & Madrid & 1716 \\
\hline 164 & $8^{\circ}$ & 1 & Osorio, Juan & $\begin{array}{l}\text { Varianum concionem et in } \\
\text { pasiones Domine epitome }\end{array}$ & & \\
\hline 165 & $4^{0}$ & 1 & 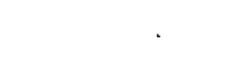 & $\begin{array}{l}\text { Oficia propia sanctorum } \\
\text { Toletana eclesia }\end{array}$ & Amberes & \\
\hline 166 & $4^{0}$ & 1 & & Breviario Romano & Madrid & 1670 \\
\hline 167 & $4^{0}$ & 1 & Quintero, Jacinto & Panegiricos sagrados & Madrid & 1651 \\
\hline 168 & $4^{\circ}$ & 1 & Quintero Jacinto & $\begin{array}{l}\text { Discursos evangelicos de } \\
\text { Cuaresma }\end{array}$ & Madrid & 1652 \\
\hline 169 & fol & 1 & Parra, Juan Martinez & $\begin{array}{l}\text { Luz de verdades catholicas } \\
\text { y expliacion de la doctrina } \\
\text { christiana }\end{array}$ & Barcelona & 1755 \\
\hline 170 & $4^{\circ}$ & 1 & Pichon, Francisco & Opusculum de Deo incarnato & Toledo & 1629 \\
\hline 171 & $4^{\circ}$ & 1 & Paredes, Bernardo & $\begin{array}{l}\text { Armonia mistica y moral para } \\
\text { divertir del vicio y aficionarse } \\
\text { a la virtud }\end{array}$ & $i ?$ & 1649 \\
\hline 172 & fol & 1 & Ceballos, Luis Ignacio & $\begin{array}{l}\text { Vida y virtudes de la Madre } \\
\text { Sor Maria Angela de Astoch }\end{array}$ & Madrid & 1733 \\
\hline
\end{tabular}

Actas del I Congreso de Historia de la Iglesia y el Mundo Hispánico Hispania Sacra, 52 (2000) 


\begin{tabular}{|c|c|c|c|c|c|c|}
\hline Ref. & Tan. & Vol. & Autor & Titulo & Lugar & Afio \\
\hline 173 & fol & 1 & Sancio, Juan & $\begin{array}{l}\text { Selecta et practicae } \\
\text { disputtationes jer... paxim in } \\
\text { administratione sacramentorum } \\
\text { eucharistiacex penitentia } \\
\text { ocurentium }\end{array}$ & Madrid & 1624 \\
\hline 174 & fol & 1 & Suarez, Francisco & $\begin{array}{l}\text { Tractatus quinque teologici ad } \\
\text { prima secunda Divi Thoma }\end{array}$ & Lyon & 1628 \\
\hline 175 & fol & 1 & Suarez P. Francisco & $\begin{array}{l}\text { Parte segunda summa } \\
\text { theologia, toinus alter } \\
\text { completens tractatum } \\
\text { secundum de opere sex dierum } \\
\text { ac tertium de anima }\end{array}$ & Lyon & 1621 \\
\hline 176 & fol & 1 & Suarez P. Francisco & $\begin{array}{l}\text { Comientarium disputationem in } \\
\text { tertiam partem Divi Thomae } \\
\text { tomus primus, prionum viginti } \\
\text { sex quartionum eius partis } \\
\text { expositionem complectens }\end{array}$ & Lyon & 1614 \\
\hline 177 & fol & 1 & Suarez P. Francisco & $\begin{array}{l}\text { Pars secunda summa theologia } \\
\text { de Deo, renum omnium } \\
\text { creatore }\end{array}$ & Lyon & 1620 \\
\hline 178 & fol & 1 & Suarez P. Francisco & $\begin{array}{l}\text { Opus de triplici virtute } \\
\text { theologica, fide, spe at } \\
\text { charitate }\end{array}$ & Aschaenburg & 1622 \\
\hline 179 & fol & 1 & Suarez P. Francisco & $\begin{array}{l}\text { Metafhisicanum disputationum } \\
\text { in quibus et univessa naturatis } \\
\text { theologia ordinate traditur }\end{array}$ & Salamanca & 1627 \\
\hline 180 & fol & 1 & Suarez P. Francisco & $\begin{array}{l}\text { Quationes omnes ad duodecim } \\
\text { Aristotelis libros pertinentes, } \\
\text { accurate disputantur }\end{array}$ & Salamanca & 1627 \\
\hline 181 & fol & 1 & Rivadeneira P. Pedro & Libro de las vidas de los santos & Madrid & 1665 \\
\hline 182 & fol & 1 & Ramirez, Vicente & $\begin{array}{l}\text { Tractatus de divine } \\
\text { predestinatione }\end{array}$ & Alcala & 1702 \\
\hline 183 & fol & 2 & Ramirez P. Vicente & Tractatus de scientia Dei & Madrid & 1608 \\
\hline 184 & fol & 1 & Villalobos Fr. Enrique & $\begin{array}{l}\text { Suma de la theologia moral y } \\
\text { camonica }\end{array}$ & Madrid & 1650 \\
\hline 185 & fol & 1 & Villalobos Fr. Enrique & $\begin{array}{l}\text { Suma de la theologia moral y } \\
\text { canonica }\end{array}$ & Barcelona & 1640 \\
\hline
\end{tabular}

Actas del I Congreso de Historia de la Iglesia y el Mundo Hispánico Hispenia Sacra, 52 (2000) 


\begin{tabular}{|c|c|c|c|c|c|c|}
\hline Ref. & $\mathrm{Tam}$ & Wol & Autor & Titulo & Lugar & $A \not \tilde{o} O$ \\
\hline 186 & fol & 1 & Villalobos Fr. Enrique & $\begin{array}{l}\text { Epilogas summarum, sive } \\
\text { rerum omnium, amplissimum } \\
\text { compendium, qua in universis } \\
\text { moralis tractantur }\end{array}$ & Cuenca & 1650 \\
\hline 187 & fol & 1 & Tamburino P. Tomas & Theologia moral & Venecia & 1748 \\
\hline 188 & $8^{\circ}$ & 1 & Toledo, Francisco & Suma mofal & Ruan & 1625 \\
\hline 189 & 8 & 1 & Alagona, Pedro & $\begin{array}{l}\text { Compendium manualis Nav... } \\
\text { et comentaris eiusdem de usuris }\end{array}$ & Roma & 1503 \\
\hline 190 & $4^{\circ}$ & 1 & Arias, Francisco & Aprovechamiento espiritual & Sevilla & 1596 \\
\hline 191 & $4^{\circ}$ & 1 & Arbiol, Antonio & $\begin{array}{l}\text { Mistica fundamental de Christo } \\
\text { Sefior Nuestro }\end{array}$ & Barcelona & 1748 \\
\hline 192 & $4^{a}$ & 1 & Bernardez, Jacob & Sermones & Coimbra & 1714 \\
\hline 193 & $4^{\circ}$ & 1 & Bernardez P. Jacob & Platicas & Coimbra & 1716 \\
\hline 194 & $4^{0}$ & 1 & & Biblia Sacra & Lyon & 1573 \\
\hline 195 & $4^{\circ}$ & 1 & Busenbaum P. Herman & Medulla theologia moralis & Madrid & 1664 \\
\hline 196 & $4^{0}$ & 1 & Busenbaum P. Herman & Medulla theologia moralis & Barcelona & 1705 \\
\hline 197 & $8^{a}$ & I & Danielo, Gabriel & $\begin{array}{l}\text { Viaggio por lo mondo di } \\
\text { Cartegio }\end{array}$ & Genova & 1703 \\
\hline 198 & fol & 1 & Diana P. Antonio & $\begin{array}{l}\text { Pars septima resolutiones } \\
\text { moralium }\end{array}$ & Lyon & 1645 \\
\hline 199 & fol & 1 & Diana P. Antonio & $\begin{array}{l}\text { Pars octava resolutiones } \\
\text { moralium }\end{array}$ & Madrid & 1647 \\
\hline 200 & fol & 1 & Diana P. Antonio & $\begin{array}{l}\text { Pars nona resolutiones } \\
\text { moralium }\end{array}$ & Lyon & 1650 \\
\hline 201 & fol & 1 & Diana P. Antonio & $\begin{array}{l}\text { Pars decima resolutiones } \\
\text { moralium }\end{array}$ & Madrid & 1653 \\
\hline 202 & fol & 1 & Diana P. Antonio & $\begin{array}{l}\text { Pars undecima resolutiones } \\
\text { moralium }\end{array}$ & Lyon & 1662 \\
\hline 203 & 8 & 1 & Godinez, Miguel & Practica de la teologia mistica & Pamplona & 1690 \\
\hline 204 & $4^{\circ}$ & 1 & Gutienrez, Antonio & Sermones varios & Madrid & 1736 \\
\hline 205 & $4^{\circ}$ & 1 & Gutierrez P. Antonio & Sermones varios & Madrid & 1738 \\
\hline 206 & $4^{\circ}$ & 1 & Gutierrez P. Antonio & Semones varios & Madrid & 1739 \\
\hline 207 & $4^{\circ}$ & 1 & Cubillas, F. Sales & $\begin{array}{l}\text { Practica del amor de Dios- } \\
\text { Traduc. frances }\end{array}$ & Zaragoza & 1673 \\
\hline 208 & $4^{\circ}$ & 1 & Catelvi, Julian & $\begin{array}{l}\text { Comentarios in libros phisica } \\
\text { aristotelica }\end{array}$ & Valencia & 1726 \\
\hline
\end{tabular}

Actas del I Congreso de Historia de la Iglesia y el Mundo Hispánico Hispania Sacra, 52 (2000) 


\begin{tabular}{|c|c|c|c|c|c|c|}
\hline $\operatorname{Ref}$. & Tam & Vol. & Autor & Titulo & Lugar & Año \\
\hline 209 & $4^{\circ}$ & 1 & Bonacina P. Martin & $\begin{array}{l}\text { Compendium absolutissimum } \\
\text { omnibus cura animarum } \\
\text { gerentibus apuri utile }\end{array}$ & Zaragoza & 1636 \\
\hline 210 & $8^{\circ}$ & 1 & Bastida, Fervando & $\begin{array}{l}\text { Antidoto a las venenteas } \\
\text { consideraciones de Fr. Pablo } \\
\text { de Venecia }\end{array}$ & Leon & 1607 \\
\hline 211 & $8^{a}$ & 1 & Bustamante, Juan & Ceremonias de la Misa & Madrid & 1659 \\
\hline 212 & $8^{\circ}$ & 1 & & $\begin{array}{l}\text { Courtes prieres pour dire a la } \\
\text { maison }\end{array}$ & Paris & 1667 \\
\hline 213 & $8^{\circ}$ & 1 & Causino P. Nicolas & La Corte Santa & Bolonia & 1648 \\
\hline 214 & $4^{\circ}$ & 1 & Lulio, Raimundo & $\begin{array}{l}\text { Ars generalis ultima } \\
\text { venęrabilis magistri ac Doctoris }\end{array}$ & & \\
\hline 215 & $4^{\circ}$ & 1 & Lumbier, Raimumido & $\begin{array}{l}\text { Noticia de las sesenta y cinco } \\
\text { proposiciones nuevamente } \\
\text { condenadas por Nro. Ssmo. } \\
\text { P. Inocencio XI }\end{array}$ & Madrid & 1682 \\
\hline 216 & $4^{\circ}$ & 1 & Murcia, Francisco & $\begin{array}{l}\text { Selecta octo libros phisiconum } \\
\text { Aristotelis }\end{array}$ & Madrid & 1616 \\
\hline 217 & $4^{\circ}$ & 1 & $\begin{array}{l}\text { Malpartidensi, } \\
\text { Fr.Alfonso }\end{array}$ & $\begin{array}{l}\text { Disputationes in tres libros } \\
\text { Aristotelis }\end{array}$ & Alcala & 1640 \\
\hline 218 & $4^{0}$ & 1 & $\begin{array}{l}\text { Malpartidensi } \\
\text { Fr. Alfonso }\end{array}$ & $\begin{array}{l}\text { Disputationes in octo libros } \\
\text { phisicorum. }\end{array}$ & Aicala & 1640 \\
\hline 219 & $4^{0}$ & I & Malpartidensi Fr. Alfonso & Sumulas & Alcala & 1640 \\
\hline 220 & $8^{\circ} \mathrm{m}$ & 1 & & $\begin{array}{l}\text { Ratio atque institutio } \\
\text { estudionum Societetis lesu } \\
\text { authoritate setima } \\
\text { congregationes generalis }\end{array}$ & Amberes & 1635 \\
\hline 221 & $4^{0}$ & 1 & Rubio, P. Antonio & $\begin{array}{l}\text { Dialecticam Aristotelis } \\
\text { comentari questiones }\end{array}$ & Madrid & 1620 \\
\hline 222 & $4^{0}$ & 1 & Rubio, P. Antonio & $\begin{array}{l}\text { Comentaris in octo libros } \\
\text { Aristotelis de phisico auditu }\end{array}$ & Alcala & 1613 \\
\hline 223 & $4^{0}$ & 1 & $\begin{array}{l}\text { Peinado, P. Ignacio } \\
\text { Francisco }\end{array}$ & Logica & Alcala & 1620 \\
\hline 224 & $4^{0}$ & 1 & $\begin{array}{l}\text { Peinado, P. Ignacio } \\
\text { Francisco }\end{array}$ & Phisica & Alcala & 1680 \\
\hline 225 & $4^{\circ}$ & 2 & $\begin{array}{l}\text { Peinado, P. Ignacio } \\
\text { Francisco }\end{array}$ & De generatione & Alcala & 1690 \\
\hline
\end{tabular}

Actas del I Congreso de Historia de la Iglesia y el Mundo Hispánico Hispania Sacra, $\$ 2$ (2000) 


\begin{tabular}{|c|c|c|c|c|c|c|}
\hline Ref. & Tam. & Vol. & Autor & Titulo & Lugar & Anto \\
\hline 226 & $4^{\circ}$ & 2 & $\begin{array}{l}\text { Peinado, P. Ignacio } \\
\text { Francisco }\end{array}$ & De amima & Alcala & 1690 \\
\hline 227 & $4^{\circ}$ & 1 & Pinamonte, P.Juan Pedro & Sinagoga desengafifada & Madrid & 1733 \\
\hline 228 & Fol & 1 & Pinamonte, P.Juan Pedro & La religion en soledad & Madrid & 1733 \\
\hline 229 & $4^{\circ}$ & 1 & $\begin{array}{l}\text { Paravicino, Fr. Hortensio } \\
\text { Felix }\end{array}$ & $\begin{array}{l}\text { Oraciones evangelicas y } \\
\text { Pannegiricos funcrales }\end{array}$ & Madrid & 1641 \\
\hline 230 & $4^{\circ}$ & 4 & Pascual, P. Miguel Angel & Sermones panegiricos & & 1705 \\
\hline 231 & $4^{\circ}$ & 1 & Rodriguez, Alonso & $\begin{array}{l}\text { Ejercicio de perfecion y } \\
\text { virtudes christianas }\end{array}$ & Madrid & 1657 \\
\hline 232 & $4^{\circ}$ & 1 & Rivadeneira, P. Gaspar & $\begin{array}{l}\text { Predestinatione sanctorum at } \\
\text { reprobationeimpiorum }\end{array}$ & Alcala & 1652 \\
\hline 233 & $4^{0}$ & 1 & Rivadeneira, P. Gaspar & De scientia Dei & Alcala & 1653 \\
\hline 234 & $4^{\circ}$ & 1 & Rivadeneira P. Gaspar & De volumtate Dei & Alcala & 1655 \\
\hline 235 & Fol & 1 & Vazquez P. GabrieI & Opuscula moralia & Alcala & 1617 \\
\hline 236 & $4^{\circ}$ & 1 & $\begin{array}{l}\text { Maestro Sto.Thomas, } \\
\text { Fr.Juan }\end{array}$ & Antis logica $2^{\circ}$ pars & Madrid & 1640 \\
\hline 237 & $4^{\circ}$ & 1 & Toledo P. Francisco & $\begin{array}{l}\text { Instrucion de sacerdotes y } \\
\text { suma de casos de conciencia }\end{array}$ & Valencia & 1617 \\
\hline 238 & $8 \mathrm{~m}$. & 1 & Schevicavio, Gisherto & $\begin{array}{l}\text { De eclesiasticonum vita } \\
\text { moribus officis }\end{array}$ & Maguncia & 1621 \\
\hline 239 & $8^{\circ}$ & 1 & Sancher, Thomas & $\begin{array}{l}\text { Compendium totius tractatus de } \\
\text { sancto matrimonio sacramento }\end{array}$ & Lyon & 1623 \\
\hline 240 & $4^{0}$ & 1 & Soto, Juan & $\begin{array}{l}\text { Exposicion parafrastica del } \\
\text { salterio de David }\end{array}$ & Alcala & 1612 \\
\hline 241 & $4^{0}$ Bil. & 1 & Turlot, Nicolas & Thesaurus doctrina christiana & Venecia & 1736 \\
\hline 242 & $4^{0}$ & 1 & Tullench, Juan Egidio & Expositio bula sancta cruciata & Barcelona & 1637 \\
\hline \multicolumn{7}{|c|}{ Cuarto P. Miguel Jara, Predicador. } \\
\hline 243 & $4^{\circ} \mathrm{m}$ & 1 & Engelgrave, Enrique & $\begin{array}{l}\text { De coelum empireum novaris } \\
\text { et fictis constellationem } \\
\text { monstis veluatum }\end{array}$ & Colonia & 1720 \\
\hline 245 & $4^{\mathrm{a}} \mathrm{m}$ & 1 & Engelgrave, P. Enrique & $\begin{array}{l}\text { Lux evangelica sub bellum } \\
\text { sacrorum emblematum } \\
\text { recondite in omnes dominicas } \\
\text { totius annis }\end{array}$ & Colonia & 1726 \\
\hline
\end{tabular}

Actas del I Congreso de Historia de la Iglesia y el Mundo Hispánico Hispania Sacra, 52 (2000) 


\begin{tabular}{|c|c|c|c|c|c|c|}
\hline Ref. & Tam. & Vol. & Autor & Tituto & Lugar & Afio \\
\hline 246 & $4^{\circ} \mathrm{m}$. & 1 & Engelgrave, P. Enrique & $\begin{array}{l}\text { Celeste panteon sive caelum in } \\
\text { festa et gasta sanctorum }\end{array}$ & Colonia & 1727 \\
\hline 247 & $4 m$. & 1 & Engelgrave, P. Enrique & Lux evangelica & Colonia & 1626 \\
\hline 248 & $4^{\circ}$ & 1 & Engelgrave, P. Enrique & Celeste panteon-2 parte & Colonia & 1727 \\
\hline 249 & fol. & 1 & Echeverria, P. Carlos & Tractatus de angelis & Alcala & 1697 \\
\hline 250 & $4^{\circ}$ & 1 & Echeverria, Carlos & Sermones panegiricos & Alcala & 1680 \\
\hline 251 & $4^{\circ}$ & 1 & Eliseu, Antonio & Sermones varios $-1^{2}$ y $3^{\prime \prime}$ parte & Lisboa & 1740 \\
\hline 252 & $4^{\circ}$ & 1 & Elisel, Fr. Antonio & Sermones varios $-2^{a}$ parte & Lisboa & 1738 \\
\hline 253 & $4^{\circ}$ & 1 & Diana, P. Antonio & $\begin{array}{l}\text { Resolutionum moralium- } \\
1^{2} \text { y } 2^{2} \text { parte }\end{array}$ & Palermo & 1632 \\
\hline 254 & $4^{\circ}$ & 1 & Diana, P. Antonio & $\begin{array}{l}\text { Resolutionum moralium } \\
1^{4} \text { y } 2^{*} \text { parte }\end{array}$ & Sevilla & 1635 \\
\hline 256 & $4^{\circ}$ & 1 & Diana, P. Antonio & $\begin{array}{l}\text { Resolutionum moralium- } \\
3^{a} \text { parte }\end{array}$ & Zaragoza & 1633 \\
\hline 257 & $4^{\circ}$ & 1 & Diana, P. Antonio & $\begin{array}{l}\text { Resolutionum moralium- } \\
4^{4} \text { parte }\end{array}$ & Madrid & 1639 \\
\hline 258 & $4^{\circ}$ & 1 & Diana, P. Antonio & $\begin{array}{l}\text { Resolutionum moralium- } \\
5^{n} \text { y } 7 \text { parte }\end{array}$ & Madrid & 1646 \\
\hline 259 & $4^{\circ}$ & 1 & Alba, Juan & Centtarius et centuria & & \\
\hline 260 & $4^{\circ}$ & 1 & Aguilar, P. Jose & $\begin{array}{l}\text { Sermones varios - } \\
1^{\circ}-2^{0}-3^{\circ}-4^{0}-5^{\circ}-6^{\circ}-7^{\circ}\end{array}$ & Bruscias & 1704 \\
\hline 261 & $4^{\circ}$ & 1 & Aguilar, P. Jose & Sermones varios $-2^{\circ}$ y $3^{\circ}$ & Sevilla & 1704 \\
\hline 262 & $4^{*}$ & 1 & Aguilar, P. Jose & Sermones varios-4 $4^{\circ}$ & & 1715 \\
\hline 263 & $4^{\circ}$ & 1 & Aguilar, P. Jose & Sermones varios- $-5^{\circ}$ & & 1716 \\
\hline 264 & $4^{\circ}$ & 1 & Aguilar, P. Jose & Sermones varios- $-6^{\circ}$ & & 1722 \\
\hline 265 & $4^{\circ}$ & 1 & Aguilar, P. Jose & Sermones varios- $-7^{\circ}$ & & 1723 \\
\hline 266 & $4^{\circ}$ & 1 & Almeida, Cristobal & Sermones varios & Madrid & 1665 \\
\hline 267 & $4^{\circ}$ & 2 & Busenbaum, P. Herman & Medulla theologia moralis & Barcelona & 1703 \\
\hline 268 & $8^{\circ}$ & 1 & Busenbaum, P. Herman & Medulla theologia moralis & Mantua & 1660 \\
\hline 269 & fol. & 2 & Baeza, Diego & $\begin{array}{l}\text { Commenterium moralium in } \\
\text { evangelicam historiam }\end{array}$ & Lyon & 1631 \\
\hline 270 & $4^{\circ}$ & 2 & Castejon, P.Agustin & Voces del alma- $1^{\circ}$ y $2^{\circ}$ & Madrid & 1739 \\
\hline 271 & $4^{\circ}$ & 1 & Castejon, P. Agustin & Glorias de la Virgen & Madrid & 1738 \\
\hline 272 & $4^{\circ}$ & 1 & Castejon, P. Agustin & Sermones varios & Madrid & 1738 \\
\hline 273 & $8^{\circ}$ & 1 & Chrisologo, San Pedro & Perseveratuma opera homiliarum & Paris & 1612 \\
\hline
\end{tabular}

Actas del I Congreso de Historia de la Iglesia y el Mundo Hispánico Hispenia Sacra, 52 (2000) 


\begin{tabular}{|c|c|c|c|c|c|c|}
\hline Ref. & Tan. & Vol. & Autor & Titulo & Lugar & Año \\
\hline 274 & $4^{\circ} \mathrm{m} \cdot \mathrm{m}$. & 1 & Cayetano, Tomas & Suma sumula de pecatis & Lyon & 1544 \\
\hline 275 & $4^{9} \mathrm{~m}$. & 1 & & $\begin{array}{l}\text { Concordantia biblorum } \\
\text { utriusque testamento }\end{array}$ & Amberes & 1581 \\
\hline 276 & 8 & 1 & Tillucio, Vicente & $\begin{array}{l}\text { Sinopsis universae theologia } \\
\text { moralis }\end{array}$ & Paris & 1627 \\
\hline 277 & fol. & 1 & Florencia, Geronimo & $\begin{array}{l}\text { Marial-Sermones de } \\
\text { Ntra Señora }\end{array}$ & Alcala & 1625 \\
\hline 278 & $4^{\circ}$ & 1 & $\begin{array}{l}\text { Fentandez Cantos, } \\
\text { Antonio }\end{array}$ & Guia de ordenandos & Valencia & 1772 \\
\hline 279 & $4^{\circ}$ & I & $\begin{array}{l}\text { Fernandez Cantos } \\
\text { Dr. Antonio }\end{array}$ & Espejo de sacerdotes & Valencia & 1772 \\
\hline 280 & $4^{\circ}$ & 1 & $\begin{array}{l}\text { Ibañez de Villanueva, } \\
\text { Martin }\end{array}$ & Sermomes varios & & \\
\hline 281 & $4^{\circ}$ & 1 & San Alfonso, Martin & Sermones varios & Madrid & 1679 \\
\hline 282 & $4^{\circ}$ & 1 & San Juan, Isidro & $\begin{array}{l}\text { Triunfo evangelico de Christo } \\
\text { y sus santos }\end{array}$ & Madrid & 1662 \\
\hline 283 & $4^{\circ}$ & 2 & Barcia, Jose & $\begin{array}{l}\text { Dispertadores christianos- } \\
\text { Sermones doctrinales }\end{array}$ & Granada & 1685 \\
\hline 284 & $4^{\circ}$ & 4 & Barcia, D. Jose & $\begin{array}{l}\text { Dispertadores christianos. } \\
\text { Sermones doctrinales }\end{array}$ & Madrid & 1684 \\
\hline 285 & $4^{\circ}$ & 4 & Barcia, D. Jose & Dispertador christiano & Madrid & 1600 \\
\hline 286 & $4^{0}$ & 1 & Barcia, D. Jose & Dispertador christiano Marial & Cadiz & 1690 \\
\hline 287 & $4^{\circ}$ & 2 & Barcia, D. Jose & Dispertador christiano & Madrid & 1692 \\
\hline 288 & $4^{\circ}$ & 1 & Burdalue, P. Luis & Cuaresma & Madrid & 1626 \\
\hline 289 & $4^{0}$ & 1 & Belarmino, Roberto & Oficio del principe christiano & Madrid & 1624 \\
\hline 290 & $4^{\circ}$ & 1 & Alapide, Comelio & $\begin{array}{l}\text { Comentaria in onmes Divi } \\
\text { Pauli Epistolas }\end{array}$ & Amberes & 1665 \\
\hline 291 & $4^{\circ}$ & 1 & Alapide, Comelio & $\begin{array}{l}\text { Comentaria in Pentateuco } \\
\text { maioris }\end{array}$ & Amberes & 1659 \\
\hline 292 & $4^{\circ}$ & 1 & Alapide, Comelio & $\begin{array}{l}\text { Comentaria in quatıor } \\
\text { Evangelia }\end{array}$ & Amberes & 1660 \\
\hline 293 & $4^{\circ}$ & 1 & Alapide, Cornelio & $\begin{array}{l}\text { Comentarius in Evangelia } \\
\text { sancti Luca et sancti Joanis }\end{array}$ & Amberes & 1660 \\
\hline 294 & $4^{0}$ & 1 & Alapide, Cornelio & $\begin{array}{l}\text { Comentarius in Esdram } \\
\text { Nehemian Tobiam Judith } \\
\text { Esther et Macabheos }\end{array}$ & Amberes & 1661 \\
\hline
\end{tabular}

Actas del I Congreso de Historia de la Iglesia y el Mundo Hispánico Hispania Sacra, 52 (2000) 


\begin{tabular}{|c|c|c|c|c|c|c|}
\hline Ref. & $\operatorname{Tam}$ & Vol. & Autor & Titulo & Lugar & Aम̈o \\
\hline 295 & $4^{0}$ & 1 & & $\begin{array}{l}\text { Commentarii de rebus gestis in } \\
\text { negotio agregationis Privintia } \\
\text { Gallo=Belgica Societatis lesu } \\
\text { petita a Rege Christianisimo }\end{array}$ & & 1682 \\
\hline 296 & Fol & 1 & Cordara, Julio & Historia societatis Iesu & Roma & 1750 \\
\hline 297 & $4^{0}$ & 1 & Calderon, Luis Francisco & $\begin{array}{l}\text { Opusculo de oro Virtudes } \\
\text { morales christianas }\end{array}$ & Madrid & 1720 \\
\hline 298 & $4^{0}$ & 1 & Genebrardo, Gilberto & $\begin{array}{l}\text { Psalmos Davidi Vulgata } \\
\text { edictione commentarium }\end{array}$ & Lyon & 1600 \\
\hline 299 & Fol & 1 & Gallo, Jose & Dialoges de Job & Burgos & 1621 \\
\hline 300 & $4^{0}$ & 1 & Garau, P. Francisco & $\begin{array}{l}\text { Declamaciones sacras politicas } \\
\text { y morales sobre todos los } \\
\text { evangelios de la cuaresma }\end{array}$ & Valencia & 1698 \\
\hline 301 & $4^{0}$ & 1 & Garau, P. Francisco & $\begin{array}{l}\text { Declamaciones sacras politicas } \\
\text { y morales sobre todos los } \\
\text { evangelios de la cuaresma }\end{array}$ & Madrid & 1708 \\
\hline 302 & Fol. & 1 & Tamburino, P. Tomas & Explicatio Decalogui . & Venecia & 1701 \\
\hline 303 & Fol. & 1 & Tamburino, P. Tomas & Explicatio moralis iuris divini & Venecia & 1701 \\
\hline 304 & Fol. & 6 & Tostado, Alfonso & Commentaria mathei & Venecia & 1615 \\
\hline 305 & Fol. & 1 & Tostado, Ilmo. Alfonso & Opuscula varia & Venecia & 1615 \\
\hline 306 & $4^{0} \mathrm{~m}$ & 1 & Thaulleri, Juan & $\begin{array}{l}\text { Opera omnia a R. F. Laurentio } \\
\text { Sazio in latino sermonem } \\
\text { translata }\end{array}$ & Paris & 1623 \\
\hline 307 & Fol. & 1 & Silveira, Jnan & $\begin{array}{l}\text { Commentarium in Apocalipsim } \\
\text { Beati Joanis Apostoli }\end{array}$ & Lyon & 1663 \\
\hline 308 & Fol. & 1 & Silveira, Fr. Juan & $\begin{array}{l}\text { Complectens Christi Domini } \\
\text { ingresum in mundum ab } \\
\text { exordio Evangelii busque ad } \\
\text { Joannis testimonia }\end{array}$ & Lyon & 1670 \\
\hline 309 & Fol. & 1 & Silveira, Fr. Juan & $\begin{array}{l}\text { Explanans primus } \\
\text { sacratissimum annum } \\
\text { praedicationi Christi Ieso }\end{array}$ & Lyon & 1660 \\
\hline 310 & Fol & 1 & Silveira, Fr. Juan & $\begin{array}{l}\text { Explanans tertium } \\
\text { sacratissimum annum } \\
\text { praedicationi Christi Iesu } \\
\text { usque adeiuis grata in } \\
\text { Cenaculo exclusive }\end{array}$ & Lyon & 1662 \\
\hline
\end{tabular}

Actas del I Congreso de Historia de la Iglesia y el Mundo Hispánico Hispania Sacra, 52 (2000) 


\begin{tabular}{|c|c|c|c|c|c|c|}
\hline Ref. & Tan. & Vol. & Autor & Titulo & Lugar & Alio \\
\hline 311 & Fol. & 1 & Silveira, Fr. Juan & $\begin{array}{l}\text { Explanans Christi Dominidice.. } \\
\text { um in Cenaculo usque ad eius } \\
\text { admirabilen ascensionem }\end{array}$ & Lyon & 1662 \\
\hline 312 & $4^{\circ}$ & 1 & Squarzatigo, Pero Maria & $\begin{array}{l}\text { Tractatibus de dispensationibus } \\
\text { in foro conscietiae }\end{array}$ & Madrid & 1727 \\
\hline 313 & Fol. & 1 & $\begin{array}{l}\text { Quirin de Salazar, } \\
\text { Femando }\end{array}$ & $\begin{array}{l}\text { Inmaculata deiparae Virginis } \\
\text { Conceptionis defensio }\end{array}$ & Alcala & 1618 \\
\hline 314 & $4^{\circ}$ & 1 & & Quaresma complutense & Alcala & 1624 \\
\hline 315 & Fol. & 1 & Ponte, Luis & $\begin{array}{l}\text { Expositio moralia in Cantico } \\
\text { Canticonum }\end{array}$ & Paris & 1662 \\
\hline 316 & $4^{\circ}$ & 2 & Pareja, Jacinto & Ferias maiores de quaresma & Madrid & 1695 \\
\hline 317 & $4^{\circ}$ & 1 & $\begin{array}{l}\text { Pueyo, Abadia } \\
\text { Fr. Francisco }\end{array}$ & Espejo evangelico & Madrid & \\
\hline 318 & $4^{\circ}$ & 3 & Rivadeneira, P. Pedro & Flos Sanctonum & Madrid & 1616 \\
\hline 319 & Fol. & 2 & Ramirez, P. Vicente & $\begin{array}{l}\text { Tractatus de divina } \\
\text { predestinatione }\end{array}$ & Alcala & 1602 \\
\hline 320 & Fol. & 2 & Rodriguez Coronel, Juan & $\begin{array}{l}\text { Sermones exonatorios y de } \\
\text { cuaresma }\end{array}$ & Madrid & 1695 \\
\hline 321 & Fol. & 1 & Lanuza, Jeronimo & $\begin{array}{l}\text { Homilias sobre los evangelios } \\
\text { que la Iglesia Santa propone en } \\
\text { los dias de cuaresma }\end{array}$ & Barbastro & 1622 \\
\hline 322 & Fol. & 1 & Lorino, Juan & $\begin{array}{l}\text { Commentarium in libros } \\
\text { psalmonum }\end{array}$ & Lyon & 1617 \\
\hline 323 & Fol. & 1 & Lorino, P. Juan & $\begin{array}{l}\text { Commentarium in libros } \\
\text { psalmonum }\end{array}$ & Lyon & 1614 \\
\hline 324 & Fol. & 1 & Lorino, P. Juan & $\begin{array}{l}\text { Commentarium in libros } \\
\text { psalmorum }\end{array}$ & Lyon & 1616 \\
\hline 325 & Fol. & 1 & Lorino, P. Juan & Commentari in Librum Numeri & Lyon & 1622 \\
\hline 326 & Fol. & 1 & Lorino, P. Jum & $\begin{array}{l}\text { Commentaria in Acta } \\
\text { Apostolonum }\end{array}$ & Lyon & 1605 \\
\hline 327 & $4^{\circ}$ & 4 & $\begin{array}{l}\text { Lafiaut? Obispo de } \\
\text { Sirteron? }\end{array}$ & Sermones & Valencia & 1754 \\
\hline 328 & Fol. & 1 & De Vega, Alonso & $\begin{array}{l}\text { Suma, o Nueva Recopilacion- } \\
\text { Practica del fuero interior }\end{array}$ & Madrid & 1548 \\
\hline 329 & $8^{\circ}$ & 1 & Vieyra, P. Antonio & Sermones varios & Madrid & 1711 \\
\hline 330 & $8^{\circ}$ & 9 & Vieyra, P. Antonio & Sermones varios & Madrid & 1700 \\
\hline 331 & $8^{\circ}$ & 2 & Vieyre, P. Antonio & Sermones varios & Madrid & 1712 \\
\hline
\end{tabular}

Actas del I Congreso de Historia de la Iglesia y el Mundo Hispánico Hispania Sacra, 52 (2000) 


\begin{tabular}{|c|c|c|c|c|c|c|}
\hline Ref. & Tan & Vol. & Autor & Titulo & Lugar & Aก̃o \\
\hline 332 & 8 & 4 & Vieyra, P. Antonio & Sermones varios & Madrid & 1713 \\
\hline 333 & $8^{\circ}$ & 1 & Vieyra, P.Antonio & Sermones varios & Madrid & 1714 \\
\hline 334 & $4^{\circ}$ & 1 & Vieyra, P. Antonio & Sermones verios & Lisboa & 1715 \\
\hline 335 & $4^{\circ}$ & 1 & Vieym, P.Antonio & Sermones varios & Lisboe & 1679 \\
\hline 336 & $4^{\circ}$ & $\mathbf{1}$ & Vieyra, P. Antonio & Sermones varios & Lisboa & 1682 \\
\hline 337 & $4^{\circ}$ & 1 & Vieyra, P. Antonio & Sermones varios & Lisboa & 1683 \\
\hline 338 & $4^{\circ}$ & 1 & Vieyra, P.Antonio & Sermones varios & Listora & 1685 \\
\hline 339 & $4^{\circ}$ & 1 & Rodriguez, P. Alonso & $\begin{array}{l}\text { Ejercicio de perfecion y } \\
\text { virtudes cristianas }\end{array}$ & Madrid & 1728 \\
\hline 340 & $4^{\circ}$ & $\mathbf{1}$ & Rodriguez, P. Alouso & $\begin{array}{l}\text { Ejercicio de perfecion y } \\
\text { virtudes cristianas }\end{array}$ & Madrid & 1671 \\
\hline 341 & 8 & 1 & Reinosa, Pecto & $\begin{array}{l}\text { Oratorio sen altare portatile } \\
\text { preparetio ad Missam }\end{array}$ & Madrid & \\
\hline 342 & Fol. & 1 & Rivadeneira, P. Pedro & Flos Sanctorum & Madrid & 1601 \\
\hline 343 & $8^{\circ}$ & 1 & Sanz, Juan & $\begin{array}{l}\text { Expositio literalis et genuina } \\
\text { totius nova constitutionis } \\
\text { Apostolicaqua incipit } \\
\text { sacramentum penitentiac }\end{array}$ & Madrid & 1749 \\
\hline 344 & $8^{\circ}$ & 1 & Soario, Cipriano & Rhetorica libri tres & Lyon & 1611 \\
\hline 345 & Fol. & 2 & Spanner, Andres & Poliantea sacra & Venecia & 1741 \\
\hline 346 & Fol & 1 & La Serra, Miguel & Elogios de Christo y Maria & Zaragoza & 1640 \\
\hline 347 & $4^{\circ}$ & 1 & Sanchez, P. Tomas & Las seis alas del serafin & Madrid & 1669 \\
\hline 348 & $4^{*}$ & 1 & Semple de Tobar, Andres & Sermones varios & Madrid & 1664 \\
\hline 349 & $4^{\circ}$ & 1 & Gutierrez, P. Antomio & Sermones vespertinos & Madrid & 1736 \\
\hline 350 & $4^{*}$ & 1 & Gutierrez, P. Antonio & Sermones vespertinos & Madrid & 1739 \\
\hline 351 & $4^{\circ}$ & I & Gutiernez, Fr. Adres & Sermones varios & Valencia & 1736 \\
\hline 352 & $4^{\circ}$ & 1 & Gracian, Lorenzo & Obras - Tomo $2^{\circ}$ & Madrid & 1664 \\
\hline 353 & $4^{\circ}$ & I & & Laures Complutense & Alcala & 1666 \\
\hline 354 & $4^{\circ}$ & 1 & Loper, Pedro & $\begin{array}{l}\text { Triunfo Cesar Agustano en } \\
\text { dieciocho ldeas ingenioses y } \\
\text { sagradas }\end{array}$ & Madrid & 1687 \\
\hline 355 & $4^{*}$ & 3 & Santa Maria, Joseph & Sermones $-1^{n}, 2^{*} 3^{n} 4^{2}$ parte & Lisboa & 1750 \\
\hline 356 & $4^{\circ}$ & 1 & Santa Maria, Fr. Joseph & Sermones- $4^{2}$ parte & Lisboa & 1751 \\
\hline 357 & $4^{*}$ & 1 & Moya, P. Mateo & $\begin{array}{l}\text { Selecta questiones ex principis } \\
\text { theologia moralis tractatibus }\end{array}$ & Madrid & 1670 \\
\hline
\end{tabular}

Actas del I Congreso de Historia de la Iglesia y el Mundo Hispánico Hispania Sacra, 52 (2000) 


\begin{tabular}{|c|c|c|c|c|c|c|}
\hline Ref. & Tom. & Vol. & Autor & Titulo & Lugar & Año \\
\hline 358 & Fol. & 1 & Maldonado, Juan & $\begin{array}{l}\text { Comentarii in quatuor } \\
\text { evangelistas }\end{array}$ & Lyon & 1697 \\
\hline 359 & Fol. & 1 & Mendoza, P. Francisco & $\begin{array}{l}\text { Commentarium in Libros } \\
\text { Regum }\end{array}$ & Lyon & 1628 \\
\hline 360 & Fol. & 3 & Mendoza, P. Francisco & $\begin{array}{l}\text { Viridiarum sacrae ac profana } \\
\text { enuditionem }\end{array}$ & Lyon & 1635 \\
\hline 361 & Fol. & 1 & Moreno, Antonio & $\begin{array}{l}\text { Tesauro politico, moral, } \\
\text { alphabetico, concinatorio de, } \\
\text { maximas christianas,elogios } \\
\text { pamegiricos y asumtos varios }\end{array}$ & Madrid & $\$ 703$ \\
\hline 362 & Fol. & 1 & $\begin{array}{l}\text { Martinez de la Parra, } \\
\text { Juan }\end{array}$ & Luz de verdades catolicas & & \\
\hline 363 & $4^{0}$ & 1 & Moya, Juan & Philosophia secreta & Madrid & 1585 \\
\hline 364 & $4^{\circ}$ & 1 & Nuñez, Francisco & $\begin{array}{l}\text { Idea del Buen Pastor copiada } \\
\text { por los Santos DD } \\
\text { representadas en empresas } \\
\text { sacras }\end{array}$ & Leon & 1682 \\
\hline 365 & $4^{0}$ & 1 & Najera, P. Mamuel & Miscelaneas & Madrid & 1680 \\
\hline 366 & $4^{0}$ & 1 & Najera, P. Manuel & Sermones varios & Madrid & 1650 \\
\hline 367 & $4^{0}$ & 1 & Najera, P. Manuel & Cuaresma segunda & Madrid & 1681 \\
\hline 368 & $4^{0}$ & 1 & Najera, P. Manuel & $\begin{array}{l}\text { Discursos morales sobre los } \\
\text { evangelios de la cuaresma }\end{array}$ & Madrid & 1649 \\
\hline 369 & $4^{0}$ & 1 & Najera, P. Manuel & Sermones funebres & Madrid & 1666 \\
\hline 370 & $4^{0}$ & 1 & Najera, P. Manuel & $\begin{array}{l}\text { Azanias de David y artes de la } \\
\text { fortuna }\end{array}$ & Madrid & 1660 \\
\hline 371 & $4^{0}$ & 2 & $\begin{array}{l}\text { Natividad de Feijas, } \\
\text { Joseph }\end{array}$ & Medalla evangelica & Lisboa & 1608 \\
\hline 372 & fol. & 1 & Ormaza, P. Jose & $\begin{array}{l}\text { Grano del evangelio en la tierra } \\
\text { virgen Christo seminario de } \\
\text { toda ensefianza }\end{array}$ & Madrid & 1666 \\
\hline 373 & Fol. & 1 & Pastrana, Antonio Jose & $\begin{array}{l}\text { Empeños del poder y amor de } \\
\text { Dios en la admirable y } \\
\text { prodigiosa vida del Patriarca } \\
\text { San Joseph }\end{array}$ & Madrid & 1656 \\
\hline 374 & $4^{\circ}$ & 3 & Pascual, P. Miguel & El oyente remediado & Madrid & 1698 \\
\hline 375 & $4^{\circ}$ & 2 & Pascual, P. Miguel & $\begin{array}{l}\text { El operario instruido y oyente } \\
\text { aprovechado }\end{array}$ & Madrid & 1698 \\
\hline
\end{tabular}

Actas del I Congreso de Historia de la Iglesia y el Mundo Hispánico Hispania Sacra, 52 (2000) 


\begin{tabular}{|c|c|c|c|c|c|c|}
\hline Ref. & Tam & Vol. & Autor & Titulo & Lugar & Año \\
\hline 376 & $4^{\circ}$ & 3 & Pascual, P. Miguel & $\begin{array}{l}\text { El oyente desengafiado } \\
\text { convencido y remediado }\end{array}$ & Valencia & 1692 \\
\hline 377 & $4^{\circ}$ & 1 & Pascual, P. Miguel & $\begin{array}{l}\text { El oyente desengafiado } \\
\text { convencido y remediado }\end{array}$ & Valencia & 1698 \\
\hline 378 & $4^{\circ}$ & 2 & Seiteri, P. Pabio & El incredulo sin excusa & Madrid & 1696 \\
\hline 379 & $4^{0}$ & 2 & Seineri, P. Pablo & El christiano instruido & Madrid & 1694 \\
\hline 380 & $4^{0}$ & 1 & Seaieri, P. Pablo & El christiano instruido & Madrid & 1693 \\
\hline 381 & $4^{0}$ & 1 & Sefieri, P. Pablo & Quaresma-1 $1^{\mathrm{a}}$ y $2^{\mathrm{a}}$ parte & Madrid & 1697 \\
\hline 382 & $4^{0}$ & 1 & Seãeri, P. Pablo & Quaresma-1 $1^{\mathrm{a}}$ y $2^{\mathrm{s}}$ parte & Madrid & 1698 \\
\hline 383 & $4^{a}$ & 1 & Sefleri, P. Pablo & El confesor instruido & Madrid & 1695 \\
\hline 384 & $4^{a}$ & 1 & Senieri, P. Pablo & El devoto de Maria & Napoles & \\
\hline 385 & & 1 & & Sermones & & \\
\hline \multicolumn{7}{|c|}{ Inventario de libros impresos del, Padre Pedro Marin Bermudez Maestro de Gramatica } \\
\hline 386 & Fol. & 1 & Alcaraz, P. Bartolome & $\begin{array}{l}\text { Chrono Historia de la } \\
\text { Companija de Jesus en la } \\
\text { Provincia Toledo }\end{array}$ & Madrid & 1710 \\
\hline 387 & $4^{0}$ & 1 & Assdekim, Ricardo & Theologia tripartita & Colonia & 1737 \\
\hline 388 & $4^{\circ}$ & 1 & Diana, Fr. Gaspar & $\begin{array}{l}\text { Luz clarisima que desengaina } \\
\text { muebe y guia y aficiona a las } \\
\text { almas que aspiran a la perfecion }\end{array}$ & Madrid & 1662 \\
\hline 389 & $4^{0}$ & 1 & Vieyra, P. Antonio & Sermones varios & Madrid & 1668 \\
\hline 390 & $4^{0}$ & 2 & Hurtado, P. Gaspar & Tractatus de Sacramentis & Alcala & 1629 \\
\hline 391 & $8^{\circ}$ & 1 & San Pedro Crisologo & Homilias de San Pedro & Amberes & 1567 \\
\hline 392 & $8^{a}$ & 1 & Ferrarius, Hieronimus & Paulo Manucio & & \\
\hline 393 & $4^{a}$ & 1 & Herrera, Agustin & $\begin{array}{l}\text { Origen y progreso en la Iglesia } \\
\text { catolica }\end{array}$ & & \\
\hline 394 & $4^{0}$ & 1 & San Juan, Fr. Isidro & $\begin{array}{l}\text { Triunfo quadragesimal de } \\
\text { Christo en nuestras costumbres }\end{array}$ & Madrid & 1666 \\
\hline 395 & $8^{\circ}$ & 1 & Juvencio, Joseph & Ratione dicendi et docendi & Paris & 1611 \\
\hline 396 & Fol. & 2 & Diana, P. Antonio & Suma opera omnia & Amberes & 1656 \\
\hline 397 & Fol. & ] & Diana, P. Antonio & Resolutiones morales & Madrid & 1642 \\
\hline 398 & $8^{a}$ & 1 & Diez, Felipe & $\begin{array}{l}\text { Suma praedicantur ex omnibus } \\
\text { locis locupletissima pars } \\
\text { secunda }\end{array}$ & Venecia & 1591 \\
\hline
\end{tabular}

Actas del I Congreso de Historia de la Iglesia y el Mundo Hispánico Hispania Sacra, 52 (2000) 


\begin{tabular}{|c|c|c|c|c|c|c|}
\hline Ref. & Tans. & Vol. & Autor & Titulo & Lugar & Año \\
\hline 399 & $8^{\circ}$ & 1 & & $\begin{array}{l}\text { Decreta Congregationum } \\
\text { Generalium Societatis Iesu }\end{array}$ & Roma & 1615 \\
\hline 400 & Fol. & 1 & Trullench, P. Juan Egidio & Opus morales & Valencia & 1640 \\
\hline 401 & $4^{\circ}$ & 1 & & $\begin{array}{l}\text { Theatro evangelico de } \\
\text { sermones }\end{array}$ & Alcala & 1649 \\
\hline 402 & $8^{\circ}$ & 1 & Virgilio Maron, Publio & Opera & Valencia & 1667 \\
\hline 403 & $8^{\circ}$ & 1 & Valerio Maximo & Opera & Alcala & \\
\hline 404 & $4^{\circ}$ & 1 & Vargas, Јия & $\begin{array}{l}\text { Elucidata Gramatica latina ad } \\
\text { estrictam artem redacta }\end{array}$ & Madrid & 1711 \\
\hline 405 & $8^{\circ}$ & 1 & Xentreich, Adamo & Tractatus de Deo & Roma & 1600 \\
\hline 406 & $4^{\circ}$ & 1 & Feliz, Francisco & $\begin{array}{l}\text { Tentativa Complutensis tomus } \\
\text { posterior }\end{array}$ & Alcala & 1645 \\
\hline 407 & $4^{\circ}$ & 1 & $\begin{array}{l}\text { Femandez de Ayala, } \\
\text { Lucas }\end{array}$ & $\begin{array}{l}\text { Historia de la Perversa Vida y } \\
\text { Horrenda Muerte del } \\
\text { Anthecristo }\end{array}$ & Madrid & 1649 \\
\hline 408 & $8^{\circ}$ & 1 & & Guia de Portugal & Napoles & 1685 \\
\hline 409 & Fol. & 1 & Gutiertez, P. Antonio & $\begin{array}{l}\text { Escolasticus de fide spe et } \\
\text { charitate }\end{array}$ & Madrid & 1728 \\
\hline 410 & $4^{0}$ & 1 & Gutierres, P. Antonio & Sermones & Madrid & 1736 \\
\hline 411 & $4^{\circ}$ & 1 & Gutierrez, P. Antonio & Sermones vespertinos & Madrid & 1739 \\
\hline 412 & Fol. & 1 & Gutierrez, Fr. Andres & Sermones varios & Madrid & 1738 \\
\hline 413 & Fol. & 1 & Busenhaum, Hermann & Medulla de la teologia moral & Barcelona & 1688 \\
\hline 414 & $4^{\circ}$ & 1 & Busenbaum, Hermann & Medulla de la teologia moral & Padua & 1733 \\
\hline 415 & $8^{\circ}$ & 1 & Busenbaum, Hermann & Medulla de la teologia moral & Barcelona & \\
\hline 416 & Fol. & 1 & Baera, P. Diego & $\begin{array}{l}\text { Comenteria moralia in } \\
\text { Evangelicam historiam }\end{array}$ & Paris & 1624 \\
\hline 417 & 8 & 1 & Bustamante, P. Juan & Ceremonias en la Misa & Madrid & 1651 \\
\hline 418 & $4^{\circ}$ & 1 & $\begin{array}{l}\text { Santa Cruz, Miguel } \\
\text { Jeronimo }\end{array}$ & $\begin{array}{l}\text { Aritmetica especulativa y } \\
\text { practica. El dorado contador }\end{array}$ & Madrid & 1660 \\
\hline 419 & Fol. & 1 & Calatayud, P. Pedto & $\begin{array}{l}\text { Doctrinas practicas explicadas } \\
\text { en las misiones }\end{array}$ & Valencia & 1637 \\
\hline 420 & Fol. & 1 & Calatayud, P. Pedro & $\begin{array}{l}\text { Doctrinas practicas explicadas } \\
\text { en las misiones }\end{array}$ & Valencia & 1739 \\
\hline 421 & Fol. & 1 & Causino, P. Nicolas & La Corte Santa & Barcelona & 1698 \\
\hline 422 & Fol. & 1 & Causino, P. Nicolas & Elocwentia sacra et humana & Lyon & 1636 \\
\hline 423 & Fol. & 1 & Causino, P. Nicolas & Elocuentia sacra et humana & Madrid & 1664 \\
\hline
\end{tabular}

Actas del I Congreso de Historia de la Iglesia y el Mundo Hispánico Hispania Sacra, 52 (2000) 


\begin{tabular}{|c|c|c|c|c|c|c|}
\hline Ref. & Tam. & Vol. & Autor & Titulo & Lugar & Ano \\
\hline 424 & Fol. & 1 & Causino, P. Nicolas & Elocuentia sacra et humana & Madrid & \\
\hline 425 & $4^{\circ}$ & 1 & Crespo, Andres & Tractatus de angelis & Alcala & 1651 \\
\hline 426 & $4^{\circ}$ & 1 & Garcia, P. Francisco & Sermones varios & Madrid & 1682 \\
\hline 427 & $4^{\circ}$ & 1 & Garau, P. Francisco & $\begin{array}{l}\text { El sabjo instruido de ba } \\
\text { Naturaleza en cuatro maximas }\end{array}$ & Madrid & 1667 \\
\hline 428 & 8 & 1 & Glianess, Frco. Antonio & $\begin{array}{l}\text { Suma Caneutarum? et } \\
\text { iregularitatum }\end{array}$ & Roma & 1640 \\
\hline 429 & $4^{\circ}$ & 1 & Garcia, P. Francisco & $\begin{array}{l}\text { Vida y milagros de } \\
\text { San Francisco Javier }\end{array}$ & Madrid & \\
\hline 430 & $4^{\circ}$ & 1 & Guintrez, Antonio & $\begin{array}{l}\text { Speculum amoris et doloris in } \\
\text { sacratissimo exc divinissimo } \\
\text { cor de lesu }\end{array}$ & Alejandria & 1731 \\
\hline 431 & Fol. & 1 & Onaraza, P. Joseph & $\begin{array}{l}\text { El sabio dichoso y politico } \\
\text { infeliz. }\end{array}$ & Segovia & 1662 \\
\hline 432 & $8^{\circ}$ & 1 & & $\begin{array}{l}\text { Ofitia propia sanctonum } \\
\text { Ecclesia Toletanae }\end{array}$ & Amberes & 1616 \\
\hline 433 & $8^{\circ}$ & 1 & & $\begin{array}{l}\text { Offitia de santisima Eucharistia } \\
\text { sacramento, de conceptione et } \\
\text { sancto Igario de Loyola }\end{array}$ & Napoles & 1696 \\
\hline 434 & $4^{0}$ & 1 & & $\begin{array}{l}\text { Ofitia propia sanctorum } \\
\text { Ecclesia Toletanae }\end{array}$ & Amberes & 1620 \\
\hline 435 & 80 & 1 & Ovidio & Opera & Valladolid & \\
\hline 436 & $4^{\circ}$ & 1 & Sefferi, P. Pablo & El christiano instruido & Madrid & 1694 \\
\hline 437 & $4^{\circ}$ & 2 & Sefieri, P. Pablo & El cura instruido & Madrid & 1693 \\
\hline 438 & $4^{0}$ & 1 & Sefieri, P. Pablo & El cura instruido & Madrid & 1695 \\
\hline 439 & $4^{\circ}$ & 1 & Silvia, Manuei & Silva concinatoria & Evora & 1716 \\
\hline 440 & $8^{\circ}$ & 1 & Senense, Antonio & $\begin{array}{l}\text { Pestila seu expositio aurea } \\
\text { Sancti Thomae Aquinatio }\end{array}$ & Lyon & 1563 \\
\hline 441 & Fol. & 1 & Puente, P. Luis & $\begin{array}{l}\text { Meditaciones de los misterios } \\
\text { de Nuestra santa fe }\end{array}$ & & \\
\hline 442 & $8^{\circ}$ & 1 & Puente, P. Luis & Obras espirituales & Madrid & 1690 \\
\hline 443 & $8^{\circ}$ & 1 & Pinamonti, P.Juan & El director de las almas & Valencia & 1731 \\
\hline 444 & $4^{\circ}$ & 1 & Paredes, Fr. Bernardo & $\begin{array}{l}\text { La armonia mistica y moral } \\
\text { para disentar del vicio }\end{array}$ & Madrid & 1652 \\
\hline 445 & $8^{\circ}$ & 1 & Partrentio, Nicolas & Universalis geografia elementa & Napoles & 1692 \\
\hline 446 & $4^{\circ}$ & 1 & Ximeno, Pablo & $\begin{array}{l}\text { Ceremonial de la Misa y Oficio } \\
\text { Divino }\end{array}$ & Valencia & 1650 \\
\hline
\end{tabular}

Actas del I Congreso de Historia de la Iglesia y el Mundo Hispanico Hispania Sacra, 52 (2000) 


\begin{tabular}{|c|c|c|c|c|c|c|}
\hline Ref. & Tams. & Vol. & Autor & Titulo & Lugar & $A \tilde{n} 0$ \\
\hline 447 & $4^{0}$ & 1 & & $\begin{array}{l}\text { Rationale divinorum offitionum } \\
\text { quibus cumque sacerdotibus }\end{array}$ & & \\
\hline 448 & Fol. & 1 & $\begin{array}{l}\text { Lusitaro Roderico, } \\
\text { Fr. Manuel }\end{array}$ & $\begin{array}{l}\text { Questiones regulares et } \\
\text { canonica }\end{array}$ & Salamanca & 1598 \\
\hline 449 & Fol. & 1 & Rodriguez, Fr. Alonso & Ejercicio de perfecion & Barcelona & 1695 \\
\hline 450 & Fol. & 1 & Rodriguez, Manuel & $\begin{array}{l}\text { Explicacion de la Bula de la } \\
\text { Santa Cruzada }\end{array}$ & Salamanca & 1602 \\
\hline 451 & $4^{a}$ & 1 & Navarro, Pedro & $\begin{array}{l}\text { Meditiationes in foro } \\
\text { conscientiae }\end{array}$ & Toledo & 1597 \\
\hline 452 & $8^{0}$ & 1 & $\begin{array}{l}\text { Nieremberg, } \\
\text { P. Juan Eusebio }\end{array}$ & De arte voluntatis & Lyon & 1631 \\
\hline 453 & $4^{0}$ & 7 & Najera, P. Manıel & $\begin{array}{l}\text { Discursos morales sobre los } \\
\text { Evangelios de Cuaresma }\end{array}$ & Madrid & 1649 \\
\hline 454 & & 1 & & $\begin{array}{l}\text { Panegiricos de festividades } \\
\text { de Ntra. Sra }\end{array}$ & Madrid & 1651 \\
\hline 455 & & 1 & & $\begin{array}{l}\text { Panegiricos de festividades } \\
\text { de varios santos }\end{array}$ & Madrid & 1655 \\
\hline 456 & & 1 & & $\begin{array}{l}\text { Sermones del Santisimo } \\
\text { Sacramento }\end{array}$ & Madrid & 1669 \\
\hline 457 & & 1 & Viseno, Diego & $\begin{array}{l}\text { Predicables para todos los } \\
\text { domingos de Pentecostes }\end{array}$ & Barcelona & 1630 \\
\hline 458 & $4^{0}$ & 1 & La Selva, Fr. Zacarias & Anmus Apostolicus & Venecia & 1655 \\
\hline 459 & $4^{0}$ & 1 & Laraga, Francisco & $\begin{array}{l}\text { Prontuario de la Theologia } \\
\text { moral }\end{array}$ & Madrid & 1747 \\
\hline 460 & $4^{a}$ & 1 & Losada, Luis & Instrucion dialectica & Salamanca & 1621 \\
\hline 461 & $4^{\circ}$ & 1 & Losada, P. Luis & $\begin{array}{l}\text { Cursus Philosophica - } \\
\text { Pars Prima-Secunda-Tertia }\end{array}$ & Salamanca & 1620 \\
\hline 462 & $4^{0}$ & 1 & Losada, P. Luis & $\begin{array}{l}\text { Cursus philosophica. } \\
\text { Pars secumda }\end{array}$ & Salamanca & 1630 \\
\hline 463 & $4^{a}$ & 1 & Losada, P. Luis & $\begin{array}{l}\text { Cursus philosophica - } \\
\text { Pars tertia }\end{array}$ & Salamanca & 1635 \\
\hline 464 & $8^{\circ}$ & 1 & & $\begin{array}{l}\text { Libri Regum Quatuor } \\
\text { paralelipomenon secundus }\end{array}$ & & \\
\hline 465 & $4^{0}$ & 2 & Avelli, Ludovico & $\begin{array}{l}\text { Medulla Theollogica ex } \\
\text { sacris scripturas }\end{array}$ & Venecia & 1657 \\
\hline 466 & $4^{a}$ & 1 & Arbiol, Fr. Antonio & Desengaños misticos & Zaragoza & 1729 \\
\hline
\end{tabular}

Actas del 1 Congreso de Historia de la Iglesia y el Mundo Hispánico Hispania Sacra, 52 (2000) 


\begin{tabular}{|c|c|c|c|c|c|c|}
\hline Ref. & Tam. & $\mathrm{Vol}$ & Autor & Titulo & Lugar & Año \\
\hline 467 & $4^{0}$ & 1 & Avendafin, Cristobal & $\begin{array}{l}\text { Marial de las fiestas ordinarias } \\
\text { y extraordinarias de la Madre } \\
\text { de Dios }\end{array}$ & Barcelona & 1629 \\
\hline 468 & $4^{0}$ & 1 & Torres, Isidro & $\begin{array}{l}\text { Selecta Theologia de pecato } \\
\text { e gratia }\end{array}$ & Alcala & \\
\hline 469 & $4^{0}$ & 1 & $\begin{array}{l}\text { Torrejon, Pedro } \\
\text { Femando }\end{array}$ & $\begin{array}{l}\text { Expositio in universam totius } \\
\text { Aristotelis dialecticam }\end{array}$ & Alcala & 1626 \\
\hline 470 & $4^{0}$ & 1 & Santa Teresa, Joseph & $\begin{array}{l}\text { Vida virtudes y maravillas del } \\
\text { Bendito Hermano Diego de } \\
\text { Sta. Fe }\end{array}$ & & 1661 \\
\hline 471 & $8^{\circ}$ & 2 & Titelmann, Francisco & $\begin{array}{l}\text { Lectio Prima et Secunda } \\
\text { elucidatione in omnes Psalmos } \\
\text { luxta veritatem vulgatae }\end{array}$ & Lyon & 1556 \\
\hline 472 & Fol. & 1 & Mazotta, Nicolas & Theologia moralis & Napoles & 1756 \\
\hline 473 & Fol. & 1 & Martinez Parra, Juan & Luz de verdades catolicas & Madrid & 1705 \\
\hline 474 & $4^{*}$ & 1 & Molina, Antonio & Instrucion de sacerdotes & Barcelona & 1612 \\
\hline 475 & $4^{a}$ & 1 & & Moralia Gregori & & \\
\hline 476 & $4^{\circ}$ & 1 & Mendo, Andres & $\begin{array}{l}\text { Quaresma sermones para las } \\
\text { ferias mayores Domingos y } \\
\text { Semana santa }\end{array}$ & Madrid & 1662 \\
\hline 477 & $4^{\circ}$ & 1 & Moreno, P. Antonio & $\begin{array}{l}\text { Vespertinas sagradas } \\
\text { concinatorias }\end{array}$ & Madrid & 1702 \\
\hline 478 & $8^{\circ}$ & 1 & $\begin{array}{l}\text { Bocalini Romano, } \\
\text { Tiziano }\end{array}$ & Centuria segunda & Venecia & 1637 \\
\hline 479 & $8^{\circ}$ & 1 & Barcia, Ilmo D. Joseph & Despertador Christiano & Lisboa & 1685 \\
\hline 480 & $8^{\circ}$ & 1 & Barcia, Ilmo D. Joseph & Despertador Christiano & Granada & 1678 \\
\hline 481 & $8^{\circ}$ & 1 & Barcia, Ilmo D. Joseph & Despertador Christiano & Madrid & 1684 \\
\hline 482 & $8^{\circ}$ & 1 & Barcia, Ilmo D. Joseph & $\begin{array}{l}\text { Quaresma-Sermones } \\
\text { doctrinales }\end{array}$ & Granada & 1685 \\
\hline 483 & $8^{\circ}$ & 1 & Barcia, Ilmo D. Joseph & $\begin{array}{l}\text { Compendio de los cinco tomos } \\
\text { del despertador christiano }\end{array}$ & Oliva & 1685 \\
\hline 484 & $4^{0}$ & 1 & Baeza, P. Diego & $\begin{array}{l}\text { Sermones funerales y de } \\
\text { animas }\end{array}$ & Valladolid & 1645 \\
\hline 485 & $8^{\circ}$ & 1 & & Biblia Sacra & & \\
\hline 486 & $4^{\circ}$ & 1 & Bravo, Bartolome & Thesauro Hispano Latino & Madrid & 1741 \\
\hline 487 & $4^{0}$ & 1 & Sonibes, Juan Bautista & Sermones varios & Zaragoza & 1668 \\
\hline
\end{tabular}

Actas del I Congreso de Historia de la İglesia y el Mundo Hispánico Hispania Sacra, $52(2000)$ 


\begin{tabular}{|c|c|c|c|c|c|c|}
\hline Ref. & $\operatorname{Tan}$ & Vol. & Autor & Titulo & Lugar & Año \\
\hline 488 & $8^{\circ}$ & 1 & & $\begin{array}{l}\text { Semanero oficio de la Semana } \\
\text { Santa }\end{array}$ & & \\
\hline 489 & $4^{\circ}$ & 1 & Ruiz Alcobalado, Pedro & $\begin{array}{l}\text { Tratado muy utily y curioso para } \\
\text { saver bien rezar el oficio } \\
\text { romano que divulgo Pio Quinto }\end{array}$ & Toledo & 1584 \\
\hline 490 & $8^{\circ}$ & 1 & & $\begin{array}{l}\text { Reglas de la Compaffiia de } \\
\text { Jesus }\end{array}$ & Leon & 1614 \\
\hline 491 & 8 & 1 & Croiset, Juan & Discursos espirituales & Madrid & 1630 \\
\hline 492 & 8 & 1 & & $\begin{array}{l}\text { Exercicios espirituales del } \\
\text { B.P. Igracio de Loyola }\end{array}$ & Roma & 1615 \\
\hline 493 & $4^{\circ}$ & 2 & Claus, P. Joseph Ignacio & Spicelgium concinatorio & Venecia & 1746 \\
\hline 494 & $4^{\circ}$ & 1 & Garcia, P.Francisco & $\begin{array}{l}\text { Vida virtudes y milagros de } \\
\text { San Ignacio de Loyola }\end{array}$ & Madrid & 1722 \\
\hline 495 & $4^{\circ}$ & 1 & Granada, Fr. Luis & $\begin{array}{l}\text { Compendio de doctrina } \\
\text { christiana }\end{array}$ & Granada & \\
\hline 496 & $8^{\circ}$ & 1 & Granada, Fr. Luis & $\begin{array}{l}\text { Guia de pecadores y exortacion } \\
\text { de la virtud-Continuacion }\end{array}$ & Madrid & 1711 \\
\hline 497 & $8^{\circ}$ & 1 & Granada, Fr. Luis & $\begin{array}{l}\text { Guia de pecadores y doctrina } \\
\text { de la virtud }\end{array}$ & Madrid & 1711 \\
\hline 498 & $8^{\circ}$ & 1 & Granada, Fr. Luis & $\begin{array}{l}\text { De la oracion mental y vida } \\
\text { de Christo }\end{array}$ & Madrid & 1711 \\
\hline 499 & $4^{\circ}$ & 2 & Camuñas, Diego & $\begin{array}{l}\text { Explicacion de la doctrina } \\
\text { christiana }\end{array}$ & Murcia & 1709 \\
\hline 500 & $4^{\circ}$ & 1 & Camufias, Fr. Diego & Vision de cieges y alumbrados & Murcia & 1710 \\
\hline 501 & $4^{\circ}$ & 1 & & $\begin{array}{l}\text { Conciones in die sancto } \\
\text { Pasqua concio prima }\end{array}$ & & 1575 \\
\hline 502 & 8 & 1 & Stroza, Thomas & Poemata varia & Napoles & 1689 \\
\hline 503 & $8^{\circ}$ & 1 & Salatino, Carlos & Hierotticonum fraccmenta & Venecia & 1666 \\
\hline 504 & $4^{\circ}$ & 1 & Schlauter, Eduardo & Gramatica Hebraica & Roma & 1705 \\
\hline 505 & $4^{\circ}$ & 1 & Ruiz, Antonio & Sermones varios & Barcelona & 1684 \\
\hline 506 & $8^{\circ}$ & 1 & Romero, Juan Manuel & Catolica Quesimonia & & \\
\hline 507 & $4^{\circ}$ & 1 & Nieves Avendafio, Joseph & Platicas doctrinales & Valencia & 1729 \\
\hline 508 & $4^{\circ}$ & 1 & Nocetti, Carlos & $\begin{array}{l}\text { Veritas vindicata sive per } \\
\text { multe sententia authorum } \\
\text { Societatis lesul }\end{array}$ & Madrid & 1753 \\
\hline 509 & $4^{\circ}$ & 1 & Loper, Francisco & Semones & Madrid & 1678 \\
\hline
\end{tabular}

Actas del I Congreso de Historia de la Iglesia y el Mundo Hispanico Hispania Sacra, 52 (2000) 


\begin{tabular}{|c|c|c|c|c|c|c|}
\hline Ref. & Tam. & Vol. & Autor & Titulo & Lugar & Afo \\
\hline 510 & $4^{\circ}$ & 1 & Lopez, Diego & $\begin{array}{l}\text { Obras Publio Virgilio Maron } \\
\text { traducidas al castellano }\end{array}$ & Madrid & 1640 \\
\hline$\$ 11$ & $4^{\circ}$ & 1 & Lopez, Diego & $\begin{array}{l}\text { Los nueve libros de los } \\
\text { ejemplos y virtudes morales de } \\
\text { Valerio Maximo }\end{array}$ & Madrid & \\
\hline$\$ 12$ & $4^{\circ}$ & 1 & Muniessa, P. Thromas & $\begin{array}{l}\text { Cuaresma cuarta que dixo en } \\
\text { el afio } 1683\end{array}$ & Barcelona & 1685 \\
\hline 513 & $4^{\circ}$ & 1 & Madre de Dios, Jose & Los dos cercados de Ninive & Madrid & 1619 \\
\hline 514 & $8^{\circ}$ & 1 & Teusancio, Juan Diego & $\begin{array}{l}\text { Fax chronologica ad } \\
\text { omnigeram Historiam }\end{array}$ & Roma & 1701 \\
\hline 515 & $8^{\circ}$ & 1 & Mineili, Juan & Publi Terenti & Lipsia & 1730 \\
\hline 516 & 8 & 1 & Minelli, Juan & Caii Suetonis & Lipsia & 1752 \\
\hline 517 & 8 & 1 & Mineili, Juan & Tulio Ciceron Orationes selecte & Lipsia & 1751 \\
\hline 518 & 80 & 1 & Minelli, Juan & $\begin{array}{l}\text { Tulio Ciceron-De ofitiis.Libri } \\
\text { tres }\end{array}$ & Lipsia & 1751 \\
\hline 519 & $8^{\circ}$ & 1 & Minelli, Juan & Ovidii Nason -Epistolarium & Lipsia & 1728 \\
\hline 520 & $8^{\circ}$ & 1 & Minelli, Juan & $\begin{array}{l}\text { Comelio nepos. } \\
\text { De excelentibus viris }\end{array}$ & Lipsia & 1733 \\
\hline 521 & 8 & 1 & Minelli, Juan & Quinto Horatii & Venecia & \\
\hline 522 & $8^{0}$ & 1 & Marteau, Pedro & $\begin{array}{l}\text { Dialogui Provincialibus } \\
\text { quas vocant Litteris }\end{array}$ & Puzzolo? & 1695 \\
\hline \multicolumn{7}{|c|}{ Cuarto Jwan Andres Moya Operario } \\
\hline 523 & $4^{\circ}$ & 1 & Arsdekim, Ricardo & Theologia tripartita universa & Amberes & 1686 \\
\hline 524 & $4^{\circ}$ & 1 & Arsdekim, Ricardo & $\begin{array}{l}\text { Theologia universa } \\
\text { especulativa et practica }\end{array}$ & Amberes & 1686 \\
\hline 525 & $4^{\circ}$ & 1 & Arsdekim, Ricardo & Aparatus doctrina sacra & Amberes & 1686 \\
\hline 526 & Fol. & 1 & Alcaraz, P. Bartolome & $\begin{array}{l}\text { Vida virtudes y milagros de } \\
\text { San Julian , obispo de Cuenca }\end{array}$ & Madrid & 1692 \\
\hline 527 & $8^{\circ}$ & 1 & Avencino, Nicolas & Vita et doctrina lesu Christo & Bolonia & 1668 \\
\hline 528 & $8^{\circ}$ & 1 & Ville, Pedro & Grado ad Pamaso & Leon & 1742 \\
\hline 529 & $8^{\circ}$ & 1 & Ozedin, Cesar & Dialogos en espatiol y francess & Bruselas & 1665 \\
\hline 530 & $4^{\circ}$ & 1 & & Orbis terra typis & & \\
\hline 531 & $4^{\circ}$ & 1 & & $\begin{array}{l}\text { Oficio in conceptione Beatae } \\
\text { Inmaculata Maria Virginae }\end{array}$ & Madrid & 1665 \\
\hline
\end{tabular}

Actas del I Congreso de Historia de la Iglesia y el Mundo Hispánico Hispania Sacra, 52 (2000) 


\begin{tabular}{|c|c|c|c|c|c|c|}
\hline Ref. & Tam. & Vol. & Autor & Titulo & Lugar & Año \\
\hline 532 & $8^{\circ}$ & I & Lozano, Francisco & $\begin{array}{l}\text { Indice practico moral para } \\
\text { sacerdotes que confiesan } \\
\text { moribundos }\end{array}$ & Madrid & 1653 \\
\hline 533 & $8^{\circ}$ & 1 & Sacro Bosco, Juan & Sphera & Lyon & 1564 \\
\hline 534 & $4^{0}$ & 1 & Granada, Cristobal & $\begin{array}{l}\text { Historia de Ntra. Sra. de la } \\
\text { Fuensanta }\end{array}$ & Madrid & 1648 \\
\hline 535 & $8^{\circ}$ & 1 & Granada, Fr. Luis & $\begin{array}{l}\text { Libro de la oracion y la } \\
\text { meditacion }\end{array}$ & Barcelona & 1708 \\
\hline 536 & $4^{\circ}$ & 1 & San Juan, Francisca & $\begin{array}{l}\text { Carta nueva sobre la vida y } \\
\text { heroicas virtudes de la V.H. } \\
\text { maria Rosa de la Concepcion }\end{array}$ & Murcia & $i ?$ \\
\hline 537 & $8^{\circ}$ & 1 & Corville, Antonio & $\begin{array}{l}\text { Explicacion de la Gramatica } \\
\text { francesa }\end{array}$ & Madrid & 1728 \\
\hline 538 & $8^{a}$ & 1 & Concepcion, Luis & Practica de confesar & Alcala & 1663 \\
\hline 539 & $4^{\circ}$ & 1 & Calatayud, Pedro & Missiones-Tomo $2^{\circ}$ & Madrid & 1754 \\
\hline 540 & $4^{0}$ & 1 & Nieves, Fr. Joseph & Platicas doctrinales & Madrid & 1724 \\
\hline 541 & $4^{\circ}$ & 1 & Renales, Jose & $\begin{array}{l}\text { Serie pontificicia y anales } \\
\text { diocesanos }\end{array}$ & Madrid & 1742 \\
\hline 542 & $4^{\circ}$ & 1 & & $\begin{array}{l}\text { Regule instructorum Patrum } \\
\text { tertio probationes }\end{array}$ & Roma & 1693 \\
\hline 543 & $4^{0}$ & 1 & Ripalda, Jeronimo & Doctrina christiana & Pamplona & 1715 \\
\hline 544 & $4^{0}$ & 1 & & Sermones & & \\
\hline 545 & 8 & 1 & Nuffez de Prado, Jose & $\begin{array}{l}\text { Gramatica de la Lengua } \\
\text { francesa }\end{array}$ & Madrid & 1754 \\
\hline
\end{tabular}

Actas del I Congreso de Historia de la Iglesia y el Mundo Hispánico Hispania Sacra, 52 (2000) 